\title{
Secondary metabolites in fungus-plant interactions
}

\author{
Tünde Pusztahelyi ${ }^{1 *}$, Imre J. Holb ${ }^{2,3}$ and István Pócsi ${ }^{4}$ \\ ${ }^{1}$ Central Laboratory, Faculty of Agricultural and Food Sciences and Environmental Management, University of Debrecen, \\ Debrecen, Hungary, ${ }^{2}$ Faculty of Agricultural and Food Sciences and Environmental Management, Institute of Horticulture, \\ University of Debrecen, Debrecen, Hungary, ${ }^{3}$ Department of Plant Pathology, Centre for Agricultural Research, Plant \\ Protection Institute, Hungarian Academy of Sciences, Debrecen, Hungary, ${ }^{4}$ Department of Biotechnology and Microbiology, \\ Faculty of Science and Technology, University of Debrecen, Debrecen, Hungary
}

Fungi and plants are rich sources of thousands of secondary metabolites. The genetically coded possibilities for secondary metabolite production, the stimuli of the production, and the special phytotoxins basically determine the microscopic fungi-host plant interactions and the pathogenic lifestyle of fungi. The review introduces plant secondary metabolites usually with antifungal effect as well as the importance of signaling molecules in induced systemic resistance and systemic acquired resistance processes. The review

\section{OPEN ACCESS}

Edited by:

Essaid Ait Barka,

University of Reims

Champagne-Ardenne, France

Reviewed by:

Michael Wink

Heidelberg University, Germany

Xiquan Gao

Nanjing Agricultural University, China

${ }^{*}$ Correspondence:

Tünde Pusztahelyi,

Central Laboratory, Faculty of Agricultural and Food Sciences and

Environmental Management,

University of Debrecen, Böszörményi út 138, H-4032 Debrecen, Hungary pusztahelyi@yahoo.com

Specialty section:

This article was submitted to Plant Biotic Interactions, a section of the journal

Frontiers in Plant Science

Received: 29 March 2015

Accepted: 13 July 2015

Published: 06 August 2015

Citation:

Pusztahelyi T, Holb IJ and Pócsi I (2015) Secondary metabolites in fungus-plant interactions. Front. Plant Sci. 6:573. doi: 10.3389/fpls.2015.00573 also concerns the mimicking of plant effector molecules like auxins, gibberellins and abscisic acid by fungal secondary metabolites that modulate plant growth or even can subvert the plant defense responses such as programmed cell death to gain nutrients for fungal growth and colonization. It also looks through the special secondary metabolite production and host selective toxins of some significant fungal pathogens and the plant response in form of phytoalexin production. New results coming from genome and transcriptional analyses in context of selected fungal pathogens and their hosts are also discussed.

Keywords: host-pathogen interaction, phytotoxin, phytoalexin, secondary metabolite, mycotoxin

\section{Introduction}

Phytopathogenic fungi that are basically classified as necrotrophs, hemibiotrophs and biotrophs constitute one of the main infectious agents in plants, causing alterations during developmental stages including post-harvest, gaining nutrients from the plants they invade and, therefore, resulting in huge economic damage. Plants and fungi are rich sources of thousands of secondary metabolites (SMs), which consist of low-molecular weight compounds (the number of the described compounds exceeds 100,000$)$ that are usually regarded as not essential for life while their role are quite versatile (Perez-Nadales et al., 2014; Scharf et al., 2014). Here, our primary aims were to overview the fungal-plant interactions and summarize special SM productions (e.g., phytotoxins and phytoalexins) in context of these interactions. Furthermore, the review also considers data from new fungal genome and transcriptome analyses. These data have

Abbreviations: ABA, abscisic acid; AF, aflatoxin; AF B1, aflatoxin B1; AF B2, aflatoxin B2; AF G1, aflatoxin G1; DMATS, dimethylallyl tryptophan synthetase; DON, deoxynivalenol; ET, ethylene; FB1, fumonisin B1; FB2, fumonisin B2; JA, jasmonic acid; IAA, indole-3-acetic acid; ISR, induced systemic resistance; HST, host-selective toxin; NHST, non host-selective toxin; NRPS, non-ribosomal protein synthase; PCD, programmed cell death; PKS, polyketide synthase; PR, pathogenesis-related; ROS, reactive oxygen species; SA, salicylic acid; SAR, systemic acquired resistance; SM, secondary metabolite; TS, tryptophan synthetase; ZEA, zearalenone. 
hypothesized the biosynthesis of a much wider spectrum of SMs than we have actually isolated and characterized, and which could have strong effect on crop quality. In addition, these data proposed more possible physiological activities for the SMs than we thought before.

\section{Phytopathogenic Fungi}

\section{Lifestyle of Phytopathogenic Fungi}

While the initial phases of pathogenesis do not differ fundamentally between necrotrophs, hemibiotrophs and obligate biotrophic fungi, different strategies are used to acquire nutrients. Necrotrophic fungi have broader host ranges than biotrophs and often enlist cell-wall-degrading enzymes and toxins, which can be small peptides or SMs (Howlett, 2006). In contrast to necrotrophic and hemibiotrophic fungal pathogens, obligate biotrophs are entirely dependent on living plant tissue and characterized by a number of sophisticated infection structures including appressoria, penetration hyphae and infection hyphae allowing the invader to suppress plant defense responses and to gain excess to host nutrients (reviewed by Mendgen and Hahn, 2002; Schulze-Lefert and Panstruga, 2003). Biotrophs establish haustoria for nutrient uptake (Panstruga, 2003), suppress induction of host defense and reprogram metabolism (Biemelt and Sonnewald, 2006). Biotrophic fungi and their metabolism has been studied on nonobligate biotrophs, such as Cladosporium fulvum (Thomma et al., 2005), Magnaporthe grisea (Talbot, 2003) and Mycosphaerella graminicola (Palmer and Skinner, 2002; Deller et al., 2011). Much less is known about the obligate biotrophs, such as powdery mildews or rust fungi. However, it appears that biotrophy is associated with a convergent loss of secondary metabolic enzymes and reduction in genes encoding specific transporters of toxin secretion and extrusion of host defense compounds usual in necrotrophic fungi. Nevertheless, the infection strategy of necrotrophic fungi is less complex than that of obligate biotrophs. Appressoria formed by typical necrotrophs such as Cercospora, Ramularia, Rhynchosporium, Alternaria, Fusarium, Botrytis, Helminthosporium, Sclerotinia, or Verticillium species, are inconspicuous, and infection hyphae formed within the host are quite uniform (reviewed by Horbach et al., 2011). Condon et al. (2013) suggested that, while necrotrophs and hemibiotrophs employ fundamentally contrasting mechanisms of promoting disease, the tools they utilize e.g., host-selective toxins (HST) and protein effectors basically overlap.

It cannot be forgot that there are numerous examples of fungi associated with plants as symptomless endophytes (e.g., black Aspergilli, Penicillia). However, in association with host plants, the symptomless endophytes have the capacity to either develop as pathogens or saprophytes, and in either state can become producers of mycotoxins (Palencia et al., 2010), rich sources of effector molecules.

\section{Fungal Secondary Metabolites}

Fungal SMs can be divided into four main chemical classes: polyketides, terpenoids, shikimic acid derived compounds, and non-ribosomal peptides. Moreover, hybrid metabolites composed of moieties from different classes are common, as in the meroterpenoids, which are fusions between terpenes and polyketides. Analysis of available fungal genomes revealed that ascomycetes have more genes of secondary metabolism than basidiomycetes, archeo-ascomycetes, and chytridiomycetes, whereas hemi-ascomycetes and zygomycetes have none (Collemare et al., 2008). Ascomycete genomes code for on average 16 polyketide synthases (PKS), 10 non-ribosomal protein synthases (NRPS), two tryptophan synthetases (TS), and two dimethylallyl tryptophan synthetases (DMATS) with crucial importance in SM synthesis. These types of SM genes encode signature enzymes that can be enriched in secondary metabolism gene clusters and responsible for main synthesis steps of metabolites. PKS-NRPSs have been identified only in ascomycetes, with an average of three genes per species. Neurospora crassa as well as human pathogens Coccidioides spp. and Histoplasma capsulatum have a lower number of PKSs (1-9 genes), NRPS (3-6 genes) and PKS-NRPSs (0-2 genes) than other ascomycetes. High number of fungal species have more than 40 genes encoding PKS, NRPS, hybrids, TS, and DMATS in their genome, including M. grisea (45 genes) (Collemare et al., 2008) (Table 1). Synthesis of siderophores, a class of SMs for iron uptake also involves a NRPS that is also very important for the virulence of several fungi (e.g., Cochliobolus heterostrophus, C. miyabeanus, F. graminearum, and A. brassicicola) (Oide et al., 2006).

Whole-genomic analysis have identified 12-15 PKS genes in F. graminearum (Kroken et al., 2003; Gaffoor and Trail, 2006; Gao et al., 2014; Sieber et al., 2014), where six have been linked to metabolites. The remaining PKSs have no assigned products yet even though they were expressed under tested conditions. In F. graminearum, the genes with known functions (13 SM genes) cover only a minor fraction of the 51 predicted SM genes: 15 PKSs, 19 NPSs and 17 TSs were identified (Sieber et al., 2014). Besides the classical SM genes (TS, NPS, and PKS) the 114 predicted genes encoding cytochrome P450 enzymes are also suitable candidates for searching SM gene clusters. Cytochrome P450s play an essential role in many known biosynthetic pathways of fungal compounds, for instance in the biosynthesis of trichothecene mycotoxins (Tokai et al., 2007) and gibberellins (Hedden et al., 2001) (Figure 1).

In the Macrophomina phaseolina anamorphic fungus from the ascomycete family Botryosphaeriaceae, Islam et al. (2012) identified 75 putative SM genes compared with 32 in M. grisea, 37 in B. cinerea, 29 in S. sclerotiorum, and 37 in F. graminearum. A high number of NRPSs which catalyze the production of cyclic peptides including numerous toxins were also found (Table 1). In M. phaseolina an NRPS, which showed $46 \%$ identity to Cochliobolus carbonum HST1, the key enzyme responsible for the biosynthesis of the maize HST cyclic tetrapeptide HC-toxin (Figure 2) (Panaccione, 1993; Walton, 2006). In 10 different Fusarium species including $F$. graminearum, F. verticillioides, F. solani, F. culmorum, F. pseudograminearum, F. fujikuroi, $F$. acuminatum, $F$. avenaceum, $F$. equiseti, and $F$. oxysporum comparative analyses of PKSs and NRPSs led to identification of 52 NRPSs and 52 PKSs orthology groups, respectively (Hansen et al., 2015). A core collection of eight NRPSs (NRPS2-4, 6, 
TABLE 1 | Distribution of secondary metabolite gene families in selected pathogenic fungi.

\begin{tabular}{|c|c|c|c|c|c|c|c|c|}
\hline Species & PKS $^{\mathbf{a}}$ & PKS-like & NRPS $^{\mathbf{b}}$ & NRPS-like & Hybridc & DMATd & Total & References \\
\hline A. alternata & 10 & n.d. ${ }^{e}$ & n.d. & n.d. & n.d. & n.d. & $\sim 10$ & Saha et al., 2012 \\
\hline A. arborescens & 29 & n.d. & 5 & n.d. & 2 & n.d. & $\sim 36$ & Hu et al., 2012 \\
\hline C. fulvum & 10 & n.d. & 10 & n.d. & 2 & 1 & $\sim 23$ & de Wit et al., 2012 \\
\hline C. lunatus CX-3 & 16 & 1 & 6 & 10 & 2 & 1 & 36 & Gao et al., 2014 \\
\hline C. lunatus m118 & 14 & 1 & 5 & 9 & 2 & 2 & 33 & Gao et al., 2014 \\
\hline C. heterostrophus C5 & 22 & 3 & 9 & 7 & 0 & 3 & 44 & Gao et al., 2014 \\
\hline C. zea-maydis & 11 & 2 & 7 & 8 & 1 & 1 & 30 & Gao et al., 2014 \\
\hline P. nodorum & 12 & 9 & 9 & 5 & 1 & 2 & 38 & Gao et al., 2014 \\
\hline P. tritici-repentis & 14 & 6 & 12 & 6 & 1 & 0 & 39 & Gao et al., 2014 \\
\hline P. teres $f$. teres & 18 & 1 & 27 & n.d. & 2 & 1 & $\sim 49$ & Amselem et al., 2011 \\
\hline B. cinerea & 16 & 6 & 6 & 8 & 0 & 1 & 37 & Islam et al., 2012 \\
\hline S. sclerotiorum & 16 & 2 & 5 & 5 & 0 & 1 & 29 & Islam et al., 2012 \\
\hline M. grisea & 12 & 3 & 5 & 6 & 3 & 3 & 32 & Islam et al., 2012 \\
\hline M. oryzae & 23 & 2 & 8 & 6 & 5 & 3 & 47 & Gao et al., 2014 \\
\hline A. flavus & 25 & 3 & 18 & 14 & 2 & 8 & 70 & Gao et al., 2014 \\
\hline A. niger & 15 & 1 & 12 & 2 & 5 & 0 & 35 & Amselem et al., 2011 \\
\hline F. graminearum & 12 & 2 & 10 & 10 & 0 & 0 & 34 & Gao et al., 2014 \\
\hline S. turcica & 23 & 3 & 9 & 7 & 2 & 2 & 46 & Gao et al., 2014 \\
\hline M. phaseolina & 19 & 16 & 15 & 13 & 12 & 0 & 75 & Islam et al., 2012 \\
\hline
\end{tabular}

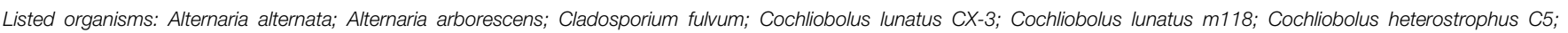

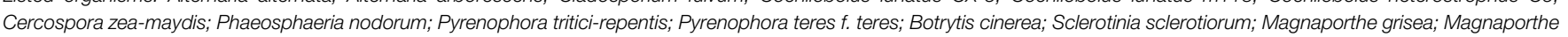
oryzae; Aspergillus flavus; Aspergillus niger; Fusarium graminearum; Setosphaeria turcica; Macrophomina phaseolina.

a polyketide synthase.

${ }^{b}$ non-ribosomal peptide synthase.

${ }^{c} P K S-N R P S$ hybrid.

${ }^{d}$ dimethylallyl tryptophan synthetase.

${ }^{e}$ not determined.

10-13) and two PKSs (PKS3 and PKS7) were only conserved in the investigated strains. The genome of the saprophytic model organism A. nidulans contained 56 putative SM core genes including 27 PKS, two PKS-like, 11 NRPS, 15 NRPS-like genes, and one hybrid NRPS-PKS gene (Yaegashi et al., 2014).

The genome sequences of $B$. cinerea and Sclerotinia sclerotiorum were determined by Amselem et al. (2011). The $B$. cinerea genome showed high sequence identity and a similar arrangement of genes to $S$. sclerotiorum. The genomes contained a significant number of genes encoding key SM enzymes (Islam et al., 2012), however, the two fungi differed strikingly in the number and diversity of SM gene clusters, which may be involved in the adaptation to different ecological niches (Islam et al., 2012). These fungi had the potential to produce $\sim 26$ and 40 main SMs, respectively, as some SM pathways have more than one key enzyme (Amselem et al., 2011).

\section{Stimuli in Fungal SM Production}

A high degree of environmental interaction, particularly sources of abiotic stress for either the host or the fungus such as drought or heat stress, also affect on the interactions (e.g., Fountain et al., 2014). Fungal genes involved in stress related responses, especially to oxidative stress, are highly represented in phytopathogenic fungi (see e.g., FSRD: Fungal Stress Response Database; Karányi et al., 2013) and fungal SM toxins often play a role in triggering these responses. Some fungal SMs, such as pigments, polyols and mycosporines, are associated with pathogenicity and/or fungal tolerance to several stress-inducing environmental factors, including temperature and UV light (Sinha et al., 2007). Moreover, environmental factors (e.g., light, temperature, $\mathrm{pH}$, calcium, and nutrients) regulate SM production in a concerted way.

Light is a requirement for deoxynivalenol (DON) toxin (Figure 3) to exert its deleterious effect similarly to the induction of programmed cell death (PCD) during Botrytis infections (Govrin and Levine, 2002). This might reflect the plant's need for light to produce reactive oxygen during the oxidative burst (Howlett, 2006). Meanwhile, regulation of toxin production is also light-dependent (Avalos and Estrada, 2010) through one of the most important light-regulatory protein complex, the velvet complex, comprising at least $F g \mathrm{Vel}$ and $\mathrm{FgVeB}$ in Fusarium with homologous components in other fungi (Yang et al., 2013; Amare and Keller, 2014). FgVe1 homolog VeA has been demonstrated to regulate trichothecene production at the level of the biosynthetic genes Tri4 and Tri5 and the transcriptional regulator genes Tri6 and Tri10 (Jiang et al., 2011; Merhej et al., 2012). Disruption of $\mathrm{VeB}$ gene led to several phenotypic defects, including suppression of aerial hyphae formation, reduced hyphal hydrophobicity, highly increased conidiation and reduced DON biosynthesis through the regulation of Tri5 and Tri6 (Jiang et al., 2012). Deletion of LaeA (a nuclear regulator from the velvet complex) homolog Lael in F. verticillioides resulted in reduced expression 
of gene clusters responsible for synthesis of the SMs bikaverin, fumonisins (Figure 3), fusaric acid and fusarins (Figure 3). Analysis of SMs in the F. verticillioides LAE1 mutant revealed differences of regulation from that of in F. fujikuroi LAE1 mutant (Wiemann et al., 2010) as bikaverin production was reduced, but the amount of fumonisin B1 (FB1) (Figure 3) remained unchanged (Butchko et al., 2012).

Nitrogen limitation have appeared to be an essential stimulus for the activation of virulence functions in phytopathogenic fungi. The ability to metabolize a wide variety of nitrogen sources enables fungi to colonize different environmental niches and survive nutrient limitations (Tudzynski, 2014). Amino acids are required for SM biosynthesis, especially for the NRPS. Amino acid limitation in fungi results in the induction of a genetic network that induces genes for enzymes of multiple amino acid biosynthetic pathways as well as for aminoacyl-tRNA synthases. Inorganic $\mathrm{N}$ sources are also affect SM production. Ammonium activated the expression of aflatoxin (AF) (Figure 4) genes (Feng and Leonard, 1998), while nitrate served as an inhibitor of AF biosynthesis of Aspergillus parasiticus (BagheriGavkosh et al., 2009). In all fungal species studied, the major GATA transcription factor AreA and its co-repressor Nmr were central players of the nitrogen regulatory network (Tudzynski, 2014). The importance of global nitrogen regulators for the development of pathogenicity was shown for M. grisea (Talbot et al., 1997) and many other fungal plant pathogens, e.g., Colletotrichum lindemuthianum, C. acutatum, and F. oxysporum (Kroll et al., 2014). In F. graminearum, which causes crop disease, nitrogen starvation activated the trichothecene pathway and induced the biosynthesis of the DON toxin (Figure 3) that was identified as a virulence factor (Desjardins et al., 1993; Audenaert et al., 2014), similar to the host selective T-toxin from Cochliobolus heterostrophus (Bipolaris maydis) (Turgeon and Baker, 2007) and the cyclic peptide AM-toxin (Figure 2) from Alternaria alternata (Markham and Hille, 2001).

Fungal toxin production is also regulated by signals or even substrates from plant. The well-characterized oxylipins (a group of diverse oxygenated polyunsaturated fatty acids) such as jasmonic acid (JA) (Figure 1) and its immediate precursor 12-oxo-phytodienoic acid are formed enzymatically in plants and accumulate in response to various stresses, in particular wounding and pathogen infection (Wasternack, 2007). These compounds are also formed non-enzymatically via the action of reactive oxygen species (ROS) (Wu and Ge, 2004), which also accumulate in response to pathogen infection, heavy metal uptake, or other stresses.

Fungal species have been shown to harbor or secrete JA and its derivatives (Miersch et al., 1999). Fungal oxylipins are able to mimic plant oxylipins; therefore, a reciprocal crosstalk was proposed between plant and fungus (Brodhagen et al., 2008), and several examples have proven this theory. The tomato-infecting F. oxysporum produced JAs using a lipoxygenase enzyme related to those found in plants, suggesting that JA biosynthesis in pathogenic fungi occurs via a pathway similar to that in plants (Brodhun et al., 2013). In Aspergillus flavus, oxylipins are molecules of quorum sensing. At low extracellular oxylipin

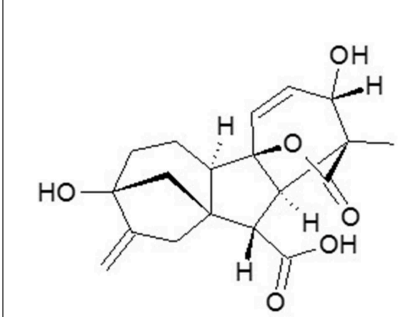

gibberellic acid<smiles>CC/C=C\CC1C(=O)CC[C@@H]1CC(=O)O</smiles>

jasmonic acid (JA)<smiles>O=C(O)Cc1c[nH]c2ccccc12</smiles>

indole-3-acetic acid (IAA)<smiles>O=C(O)c1ccccc1O</smiles>

salicylic acid (SA)<smiles>CC1=CC(=O)CC(C)(C)C1(O)/C=C/C(C)=C\C(=O)O</smiles>

abscisic acid (ABA)

FIGURE 1 | Chemical structures of some plant hormones. Source: National Center for Biotechnology Information. PubChem Compound Database (accessed Jun. 6, 2015) (Bolton et al., 2008).

concentration the cultures were characterized by increased sexual reproduction (sclerotia production), reduced conidiation (Horowitz Brown et al., 2008) and increased AF biosynthesis (Horowitz Brown et al., 2008; Affeldt et al., 2012; Amare and Keller, 2014). Moreover, deletion of oxylipin-encoding dioxygenase genes ( $p$ po genes) of $A$. flavus resulted in decreased pathogenicity on host seeds. Exposure to the exogenous plant oxylipins 9(S)-hydroperoxyoctadecadienoic (9(S)-HpODE) acid and 13(S)-hydroperoxyoctadecadienoic acid (13(S)-HpODE) influenced positively the sporulation and effected precursor sterigmatocystin and AF synthesis in A. flavus as well as in A. nidulans and $A$. parasiticus (Calvo et al., 1999). In a lipidomic approach, Scarpari et al. (2014) have proven the important role of maize oxylipins in driving SM production in A. flavus; however, the mechanism of the action has been remained unsolved.

\section{Effects of Phytotoxins on Host Plant}

Fungal phytotoxins are usually divided into host-selective toxins (HSTs) and non-host selective (NHSTs) toxins. Typically, HSTs are active only toward host plants, have unique modes of action and toxicity to the host (Otani et al., 1995); moreover, the production of the HSTs is crucial for the virulence of 
these fungi (Walton, 1996; Horbach et al., 2011; Tsuge et al., 2013). Nearly all HSTs identified so far are produced by necrotrophic pathogens of the order of Pleosporales within the class of Dothideomycetes and especially in Alternaria and Cochliobolus species (Friesen et al., 2008; Stergiopoulos et al., 2013). These HST toxins are diverse chemically ranging from low-molecular-weight compounds to cyclic peptides. Genes encoding polypeptides for biosynthesis of these HSTs have been shown to reside on a conditionally dispensable chromosome that controls host-specific pathogenicity (Hatta et al., 2002). The mechanism of host-selective pathogenesis, through the HSTs, is well understood and about 20 HSTs have been documented (Otani et al., 1995; Walton, 1996). In some cases, host sensitivity was mediated by gene-for-gene interactions, and the toxin sensitivity was mandatory for disease development (Wolpert et al., 2002). Contrarily, NHSTs are not primary determinants of host range and not essential for pathogenicity, although they may contribute to virulence. These toxins have a broader range of activity, causing symptoms not only on hosts of the pathogenic fungus but also on other plant species (Walton, 1996).

Several microbial phytotoxic compounds either inhibited an amino transferase or appeared to have such a mode of action, like cornexistin (Figure 5) from Paecilomyces variotii (Amagasa et al., 1994), which was patented as an herbicide; or tentoxin (Figure 2), a cyclic tetrapeptide from $A$. alternata, which indirectly inhibited the chloroplast development (Halloin et al., 1970). A series of structurally related fungal metabolites specifically inhibited ceramide synthase (sphinganine- $N$-acyltransferase) in plants, e.g., several analogs of AAL-toxin (A. alternata) (Figure 2) and FB1 (Figure 3) (Fusarium spp.) (e.g., Abbas et al., 1994). Fusicoccin (Figure 5) [Fusicoccum (Phomopsis) amygdali] irreversibly activated the plant plasma membrane $\mathrm{H}^{+}$-ATPase (Paiardini et al., 2014). Alternariol (Figure 2) and monomethyl alternariol are natural phytotoxins, produced by Nimbya and Alternaria, inhibited the electron transport chain (Demuner et al., 2013). Cerulenin (Figure 5) (Cephalosporium cerulens) inhibited de novo fatty acid synthesis in plastids (Laskay et al., 1985). T-toxin (a family of C35 to C49 polyketides) from C. heterostrophus (Levings et al., 1995; Inderbitzin et al., 2010), which is a HST trichothecene phytotoxin, inhibited mitochondrial respiration by binding to an inner mitochondrial membrane protein in sensitive plants, resulting in pore formation, leakage of $\mathrm{NAD}^{+}$, and other ions, as well as subsequent mitochondrial swelling (reviewed by Rocha et al., 2005). Zinniol (Figure 2) (Alternaria species and one Phoma species) bound plant protoplasts and stimulated $\mathrm{Ca}^{2+}$ entry into cells (Thuleau et al., 1988). The availability of fungal genome sequences, the knowledge of the biosynthesis of these toxins and gene disruption techniques, allows the development of tools for discovering the role of more and more toxins in plant cell death and disease.

\section{Secondary Metabolite Production on the Host's Side}

Based on their biosynthetic origins, plant SMs can be divided into three major groups, (i) flavonoids and allied phenolic and polyphenolic compounds, (ii) terpenoids, (iii) nitrogen-containing alkaloids and sulfur-containing compounds, while other researchers have classified plant SMs into more specific groups (Wink, 2003) (Table 2). Plant SMs functions as defense molecules against microbes, viruses or other competing plants or as signal molecules like hormones and attracting molecules for pollinators or seed dispersal animals. Therefore, these compounds have importance for survival and fitness (Wink, 2003).

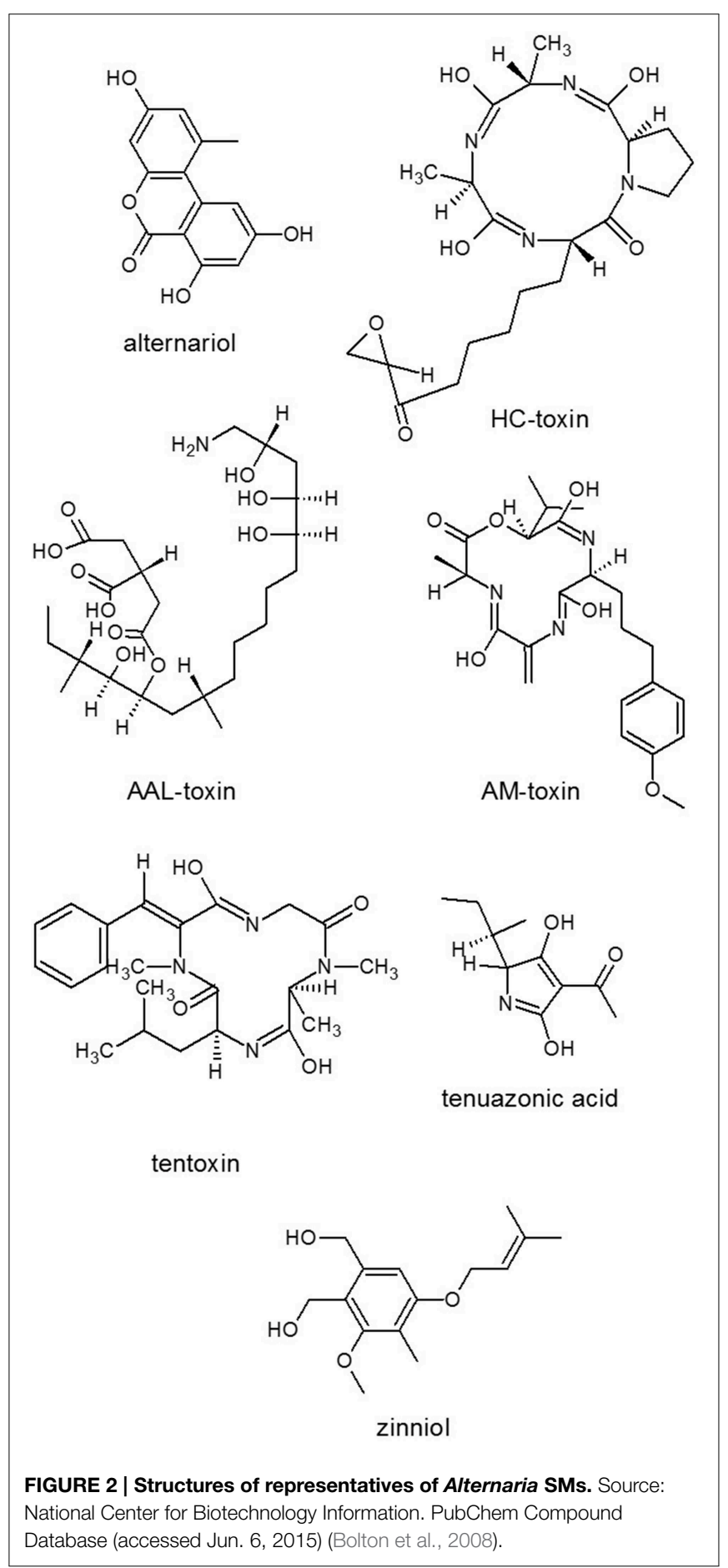




\section{Hormone Production and Plant Resistance}

Hormone biosynthetic pathways are typically involved in the regulation of plant resistance to pathogens and pests. Endogenous signaling molecules, e.g., ethylene (ET) (Ton et al., 2002), SA (Figure 1; Janda and Ruelland, 2014), JA (Figure 1; Wasternack, 2007; Van der Ent et al., 2009) and abscisic acid (ABA; Figure 1) (Hauser et al., 2011) have been associated with plant defense signaling against biotic stress. Generally, SA signaling induces defense against biotrophic pathogens, whereas JA against necrotrophic pathogens (Glazebrook, 2005).

SA synthesis is a crucial way a plant responds to a biotic attack and involved in both local and systemic resistance (Janda and Ruelland, 2014). Systemic acquired resistance (SAR) is a plant immune response (Shah et al., 2014) that is induced after a local infection and confers immunity throughout the plant

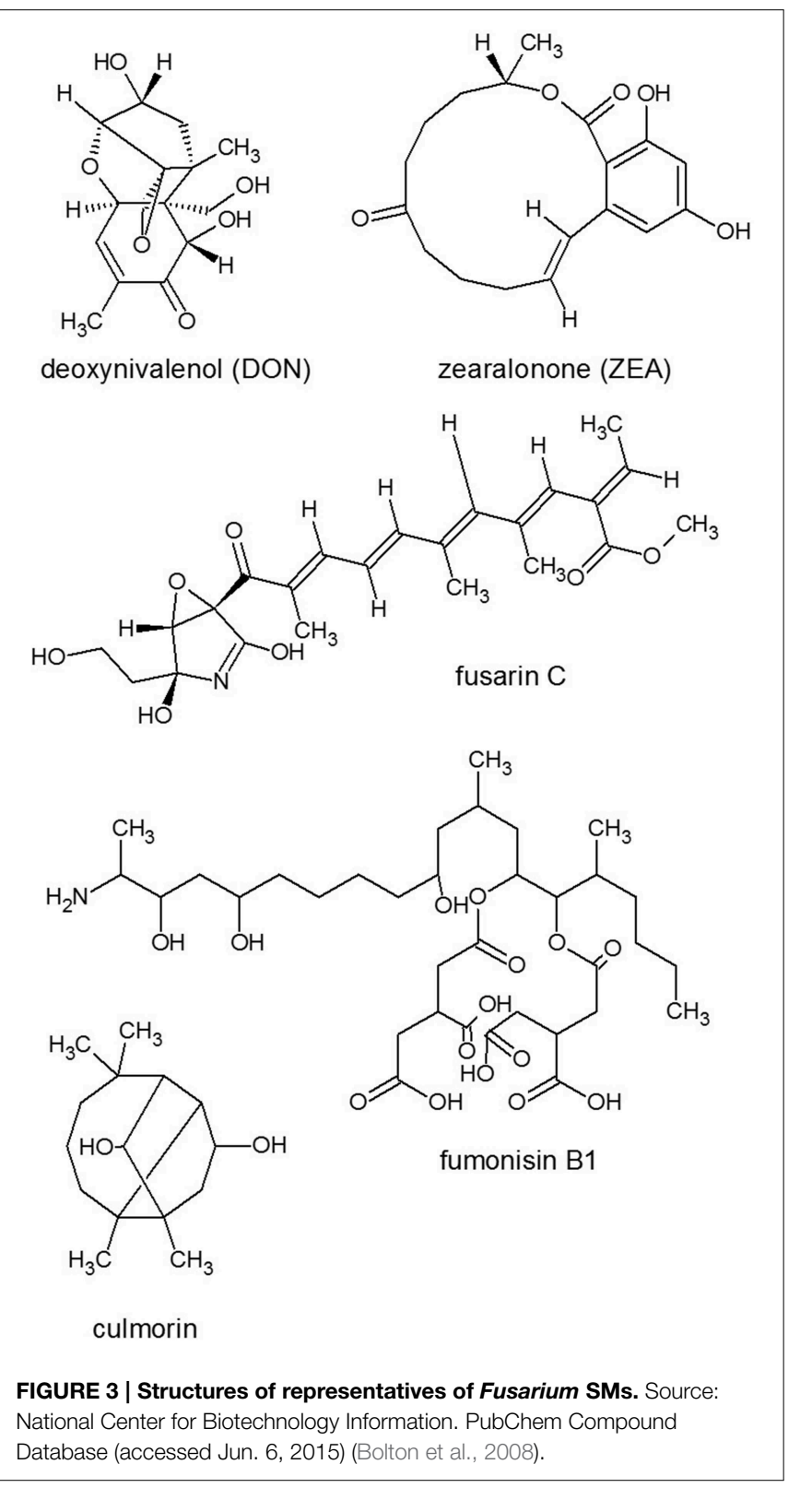

to a broad spectrum of pathogens. The onset of SAR (Durrant and Dong, 2004) is usually associated not only with increased levels of SA but additional small metabolites (Figure 6) have also been involved as effectors. Some of these metabolites have been implicated in the rapid activation of defenses in SAR in response to subsequent exposure to the pathogen that called priming (Shah et al., 2014).

The induced systemic resistance (ISR) pathway is stimulated during necrotrophic bacterial attack but was shown to protect Arabidopsis against the necrotrophic fungal pathogens Alternaria brassicicola (Ton et al., 2002), Botrytis cinerea (Van der Ent et al., 2008) and also Plectosphaerella cucumerina (Segarra et al., 2009), where SAR was ineffective (Van der Ent et al., 2009). Investigations of the regulation of ISR revealed the role of JA and ET (Ton et al., 2002; Yan et al., 2002; Kazan and Lyons, 2014). SAR and ISR were characterized by the coordinated activation of pathogenesis-related (PR) genes, many of which encode PR proteins with antimicrobial activity such as chitinases (Van Loon et al., 2006). Soluble chitin fragments released from fungal cell wall through the action of plant chitinases were found to serve as biotic elicitors of defense-related responses like phytoalexin synthesis in plants (Ren and West, 1992; Walker et al., 2003). ISR-related effect of methyl JA and SA was shown to activate also some defense enzymes (Derksen et al., 2013), which play a role to save plant cell wall and also raise the antioxidant capacity in plant cells (Yao and Tian, 2005).

The main auxin in higher plants, indole-3-acetic acid (IAA) (Figure 1), has profound effects on plant growth and development (Zhao, 2010). Only the free form of IAA and related compounds are considered to be active. The majority of produced auxin, however, is conjugated mainly to amino acids and sugars and thereby inactivated. IAA induces e.g., the production of expansins, the proteins whose function is to loosen the cell wall. But, the loose cell wall is more vulnerable to the invasion of different types of pathogens (Ludwig-Müller, 2011). Similarly to bacterial pathogens, hemibiotrophic or necrotrophic fungi produced IAA, manipulated plant growth and subverted plant defense responses such as PCD to provide nutrients for their growth and colonization (Ludwig-Müller, 2015). Magnaporthe oryzae secreted IAA in its biotrophic phase especially in the area of the infection hyphae (Tanaka et al., 2011) and, in turn, provoked rice to synthesize its own IAA at the infection sites ( $\mathrm{Li}$ et al., 2013). However, it has not been elucidated yet whether IAA production is for the manipulation of the host plant or also for the fungus's own benefit. The activation of an auxin-inducible promoter by fungal IAA indicated that the host plant responds transcriptionally to the secreted auxin. The molecular processes that lead to plant disease and also the prospects for sustainable control were reviewed by Wilson and Talbot (2009). Treatment of $F$. culmorum infected barley with IAA resulted in a reduction of symptoms and yield losses, even though IAA did not inhibit the growth of the fungus in vitro. The results indicated increases in the gene regulation for defense-associated genes (Petti et al., 2012).

Plant gibberellins are important phytohormones promoting plant growth and fungi also synthesize gibberellins among other several important terpenes (Keller et al., 2005; Khan et al., 2011). 
<smiles>COc1cc2c(c3oc(=O)c4c(c13)CCC4=O)[C@H]1C=CO[C@@H]1O2</smiles>

aflatoxin B1<smiles>COc1cc2c(c3oc(=O)c4c(c13)CCC4=O)[C@H]1CCO[C@@H]1O2</smiles>

aflatoxin B2<smiles>COc1cc2c(c3oc(=O)c4c(c13)CCOC4=O)C1C=COC1O2</smiles>

aflatoxin $\mathrm{G} 1$<smiles>CC=CC1=CC(=O)C(O)C1O</smiles>

terrein<smiles>CC(C)[C@@H]1OC(=O)COC(=O)[C@H](C(C)C)N(C)C(=O)[C@H](C(C)C)OC(=O)[C@H](C(C)C)N(C)C(=O)[C@H](C(C)C)OC(=O)[C@H](C(C)C)N(C)C1=O</smiles><smiles>CCCCCN(CC)C(C)=O</smiles>

enniatin

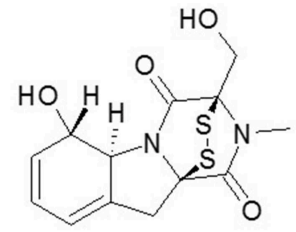

gliotoxin

FIGURE 4 | Structures of representatives of Aspergillus SMs. Source: National Center for Biotechnology Information. PubChem Compound Database (accessed Jun. 6, 2015) (Bolton et al., 2008).

However, higher plants and fungi have evolved their complex gibberellic acid (Figure 1) biosynthetic pathways convergently as it was indicated by the amino acid sequence homology analysis of the proteins in their biosythetic pathways (Hedden et al., 2001). Nevertheless, gibberellic acids produced as SMs in the rice-infecting F. fujikuroi were good examples of phytohormone mimics (Bömke and Tudzynski, 2009). Fungal gibberellins were involved in plant infection, e.g., as growth modulators like IAA, cytokinins, and ABA (Figure 1). Interestingly, other Fusarium species seem to have lost the ability to synthesize gibberellic acid, suggesting that this is an advantage for F. fujikuroi over other pathogens (Wiemann et al., 2013). Aspergillus fumigatus also produced gibberellins, and the role of this fungal species was also rectified by its regulatory effect on other phytohormones (ABA, SA, and JA) under stress condition (Khan et al., 2011).

\section{Plant Secondary Metabolites-Antifungal Compounds}

Most of the SMs like phytocassanes (Koga et al., 1995) have been reported to have antifungal properties at least in vitro. The flavonoids and allied phenolics, e.g., coumarins, lignans, and polyphenolic compounds, including tannins and derived polyphenols form one major group of phytochemicals (reviewed by Crozier et al., 2008). These compounds or their precursors are present in high concentrations in leaves and the skin of fruits and are involved in important defense processes such as UV resistance, pigmentation, disease resistance, stimulation of nitrogen-fixing nodules (Pierpoint, 2000). Phenolic compounds (reviewed by Balasundram et al., 2006) are derivatives of the pentose phosphate, shikimate, and phenylpropanoid pathways in plants. These are known to alter microbial 

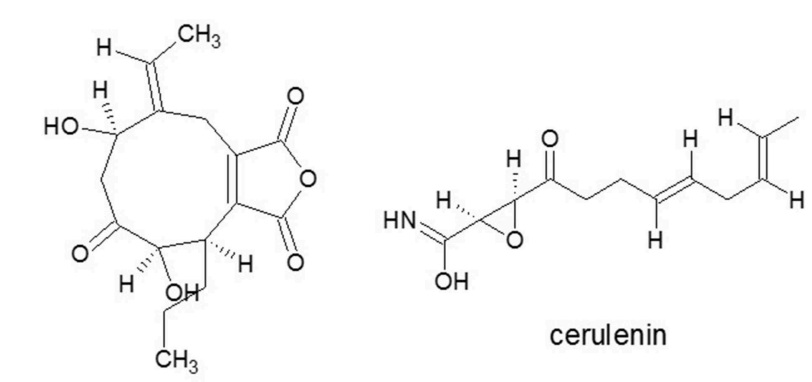

cerulenin

\section{cornexistin}

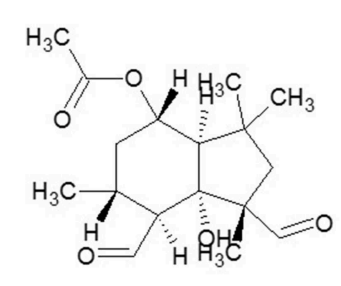

botrydial

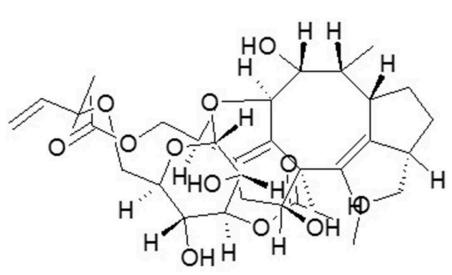

fusicoccin
FIGURE 5 | Phytotoxic SM molecules from diverse fungi. Cornexistin from Paecilomyces variotii, fusicoccin from Fusicoccum (Phomopsis) amygdali, cerulenin Cephalosporium caerulens and botrydial from Botrytis cinerea.Source: National Center for Biotechnology Information. PubChem Compound Database (accessed Jun. 6, 2015) (Bolton et al., 2008).

cell permeability and to interact with membrane proteins, which cause deformation in the structure and functionality of these proteins. These disadvantageous changes may lead to dysfunction and subsequent disruption of the membranes including the following events: (i) dissipation of the $\mathrm{pH}$ gradient and electrical potential components of the proton motive force, (ii) interference with the energy (ATP) generating and conservation system of the cell; (iii) inhibition of membranebound enzymes, and (iv) prevention of substrate utilization for energy production (De Oliveira et al., 2011; El-Mogy and Alsanius, 2012).

Antimicrobial compounds such as the steroidal glycoalkaloid saponins, e.g., avenacin (Figure 7) and $\alpha$-tomatine, restrict the growth of pathogens in the apoplast. Saponins have strong antifungal activity; the tomato saponin $\alpha$-tomatine activates phosphotyrosine kinase and monomeric G-protein signaling pathways leading to $\mathrm{Ca}^{2+}$ elevation and ROS burst by binding to cell membranes followed by leakage of cell components in F. oxysporum cells (Ito et al., 2007). Different plant species produce different types of saponins, which are effective against a wide range of pathogenic fungi (Osbourn, 1996). Terpenes are composed of several isoprene units, and can be linear or cyclic, and even saturated or unsaturated. The best-known terpenes are odoriferous plant metabolites like camphor and turpentine. The industrial and medical significances of plant terpenes, e.g., those of taxol, are reviewed by Bohlmann and Keeling (2008). In maize, sesquiterpenoid phytoalexins, zealexins (Figure 7), were discovered through characterization of physiological responses to the toxinogenic pathogen F. graminearum. Importantly, zealexins exhibited antifungal activity against several phytopathogenic fungi ( $F$. graminearum, A. flavus, Rhizopus microsporus) at physiologically relevant concentrations (Huffaker et al., 2011).

Plant antifungal metabolites are preformed inhibitors that constitutively produced in healthy plants (phytoanticipins), or they may be synthesized de novo in response to pathogen attack or various non-biological stress factors such as short-wavelength UV light, treatment with heavy metal ions (e.g., copper or mercury salts). The letter pathogen and environmental stress elicited compounds are called phytoalexins. These groups cannot be separated strictly as the same compound may be a preformed antifungal substance in one species and can be phytoalexin in another. For example, flavanone sakuranetin (Figure 8) was found to be a phytoanticipin in Ribes nigra (Atkinson and Blakeman, 1982) and in Hebe cupressoides (Perry and Foster, 1994) but was induced in the leaves of rice Oryza sativa (Kodama et al., 1992). These metabolites can be constitutively present in one organ and can be induced in another. Plant SMs usually accumulate in smaller quantities than the primary metabolites (e.g., Dewick, 2002); however, they can accumulate in particular tissues (e.g., Takanashi et al., 2012) at a higher concentration. This accumulation is regulated in a highly sophisticated manner in appropriate compartments because some plant SMs are even toxic to the plants themselves if they are mislocalized. In the compartmentation and translocation processes, both primary and secondary transporters are involved and many transporter genes, especially genes belonging to the multidrug and toxin extrusion type transporter family, have been identified as responsible for the membrane transport of SMs (Yazaki, 2006; Yazaki et al., 2008). High number of SMs are well characterized in the families Fabaceae, Solanaceae and Labiaceae (Wink, 2003) as well as in cereals (reviewed by Du Fall and Solomon, 2011). Phytoalexins in families Fabaceae and Rosaceae and in rice were reviewed by Grayer and Kokubun (2001); while, SMs in a range of crop plants from families Cruciferae, Fabaceae, Solanaceae (Pedras and Ahiahonu, 2005), Brassicaceae, Vitaceae, and Poaceae (reviewed by Ahuja et al., 2012) have also been described recently.

Phyllosphere and rhizosphere microorganisms can live in a close mutualistic association with plants or even colonize plant tissues (endophytes). Plant growth-promoting non-pathogenic microorganisms like rhizobacteria and fungi are soil-borne microbes with beneficial effects on plant performance in the rhizosphere. They can stimulate plant growth by increasing tolerance to abiotic stress or by suppressing plant diseases (Van der Ent et al., 2009). Plants may actively shape microbial communities either inhabiting their outer surface or colonizing their interior (Bednarek et al., 2010). The growing plant secretes a wide range of chemicals, e.g., in root exudates, to communicate with rhizosphere microbes (Kolattukudy et al., 1995; Suryanarayanan et al., 2009; Baetz and Martinoia, 2014) such as arbuscular mycorrhiza. Altered exudation patterns, putative direct arbuscular mycorrhiza effects, different root size and architecture, altered physiology may contribute to quantitative and qualitative microbial community changes in the mycorrhizosphere caused by arbuscular mycorrhiza 
TABLE 2 | Classification of plant secondary metabolites.

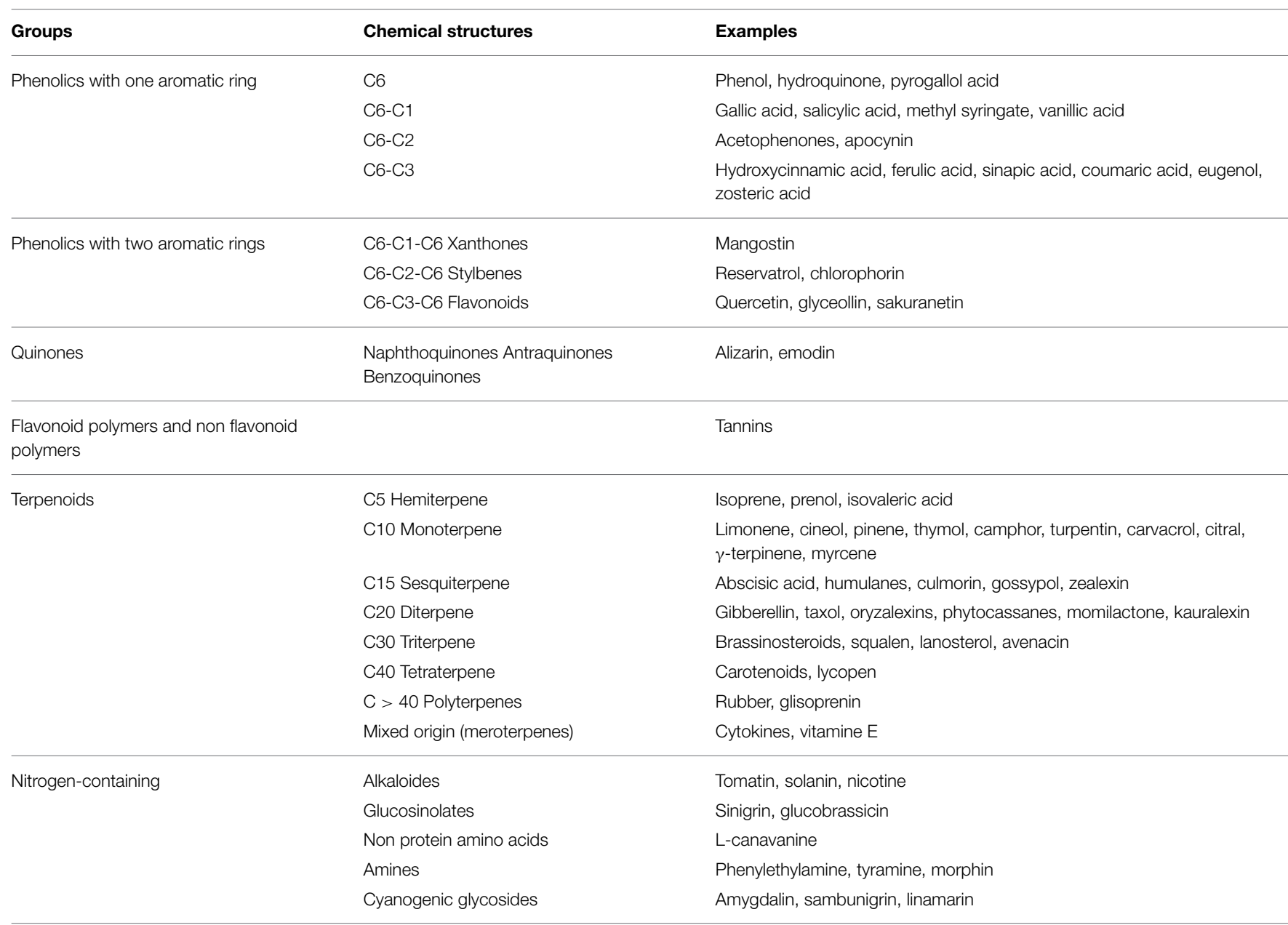

fungi (Wehner et al., 2010). Organic acids, amino acids and phenolic compounds present in root exudates play an active role in root-microbe communications (Dakora and Phillips, 2002; Tanimoto, 2005; Crowley and Kraemer, 2007; Li et al., 2013) and stimuli such as microbial elicitors trigger compositional changes in root exudates (Baetz and Martinoia, 2014). Walker et al. (2003) analyzed root exudates of Arabidopsis thaliana elicited by SA, JA and chitosan as well as by two fungal cell-wall elicitors and profiled the SMs subsequently secreted. Among the several compounds detected butanoic acid, trans-cinnamic acid, $o$-coumaric acid, $p$-coumaric acid, ferulic acid, $p$-hydroxybenzamide, methyl $p$-hydroxybenzoate, 3 -indolepropanoic acid, gallic acid, and vanillic acid were successfully inhibited the growth of F. oxysporum, Phytophthora drechsleri and Rhizoctonia solani phytopathogenic fungi.

\section{Manipulation of Programmed Cell Death}

Different fungal strategies mediate killing of the plant host cells such as secretion of low molecular weight or peptide toxins or eliciting PCD in the host by secretion of ROS (Horbach et al., 2011; Barna et al., 2012). From the host's side, chloroplasts have a critical role in plant defense as these organelles are not only sites for the biosynthesis of the plant signaling compounds: SA, JA and nitric oxide but for ROS production as well (e.g., Lee et al., 2015). Therefore, chloroplasts are regarded as important players in the induction and regulation of PCD in response to both abiotic stresses and pathogen attack. Moreover, toxin effectors from necrotrophic fungi can target one of the host's central signaling/regulatory pathway to trigger resistance $(\mathrm{R})$ gene-mediated resistance or to downregulate defense enzymes, and, as a consequence, to increase thereby host susceptibility to fungal attack (Wang et al., 2014). Aspergillus mycotoxin ochratoxin A (Figure 4) induced necrotic lesions in detached leaves through oxidative burst induction with increased ROS level and concomitant down-regulation of plant antioxidant defense enzymes (Peng et al., 2010). SMs fusarenon, nivalenol, DON, T-2, HT-2, diacetoxyscirpenol, beauvericine and neosolaniol (Figure 3) from Fusaria caused complete inhibition of seed germination and induced PCD and alteration to ascorbate metabolism in tomato protoplasts (Paciolla et al., 2004). T-2 trichothecene toxin, produced by e.g., F. sporotrichioides, also induced cell death, callose deposition, generation of hydrogen peroxide, and accumulation of SA, while DON toxin inhibited translation without induction of the elicitor-like signaling pathway in the non-host plant $A$. thaliana (Nishiuchi et al., 2006). The ascomycete Cochliobolus victoriae 


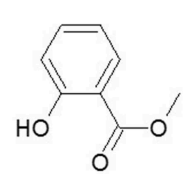

methyl salicylate

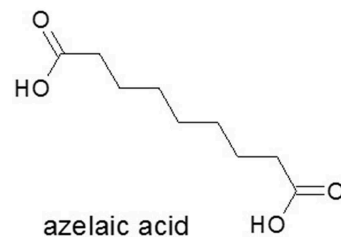

azelaic acid

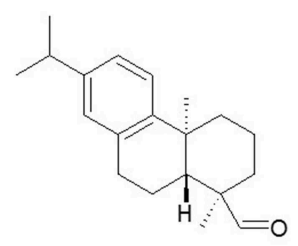

dehydroabietinal

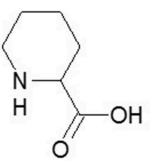

pipecolic acid
FIGURE 6 | Small metabolites as effectors in SAR signaling. Methyl salicylate, the abietane diterpenoid dehydroabietinal, pipecolic acid from lysine catabolism, and the dicarboxylic acid azelaic acid are effectors in SAR signaling additionally to SA. Source: National Center for Biotechnology Information. PubChem Compound Database (accessed Jun. 6, 2015) (Bolton et al., 2008).

is a necrotrophic fungal pathogen of Arabidopsis and oats with HST victorine, which induced defense-related responses such as phytoalexin synthesis, extracellular alkalization and PCD causing Victoria blight (Tada et al., 2005). Zhang et al. (2011) proposed that both JA and ET promote the A. alternata AAL toxin-induced PCD in detached Solanum lycopersicum leaves by disruption of sphingolipid metabolism (Spassieva et al., 2002). In Arabidopsis, free sphingoid bases were again shown to be involved in the control of PCD, presumably through the regulation of the ROS level upon receiving different developmental or environmental cues (Raffaele et al., 2009).

\section{Phytotoxins, Phytoalexins and Special SMs}

\section{Magnaporthe Grisea Species Complex}

The $M$. grisea species complex comprises many phylogenetic species (Couch and Kohn, 2002) that cause disease to some 50 grass and sedge species. These include rice, wheat, barley, maize, oats, rye, finger millet, perennial ryegrass, weed and ornamental grasses. Within this species complex, M. oryzae (previously known as M. grisea) isolates form the pathotype Oryza, which causes rice blast disease. Approximately $10-30 \%$ of the annual rice harvest is lost due to the infection. The fungus infects all aerial parts of rice, leading to leaf blast, neck and panicle rot, collar rot and node blast (reviewed by Skamnioti and Gurr, 2009).

Chemical signals are responsible for appressorium formation in M. grisea. The appressorial glue of $M$. grisea contains glycoproteins, neutral lipids and glycolipids (Ebata et al., 1998). The non-toxic plant metabolite zosteric acid (Figure 9) (Todd et al., 1993) binds water and enhances the hydrophilicity of the surface, thereby weakening the binding capacity of the appressorial glue, which is highest with hydrophobic surfaces. Therefore, zosteric acid inhibits spore adhesion and infection by

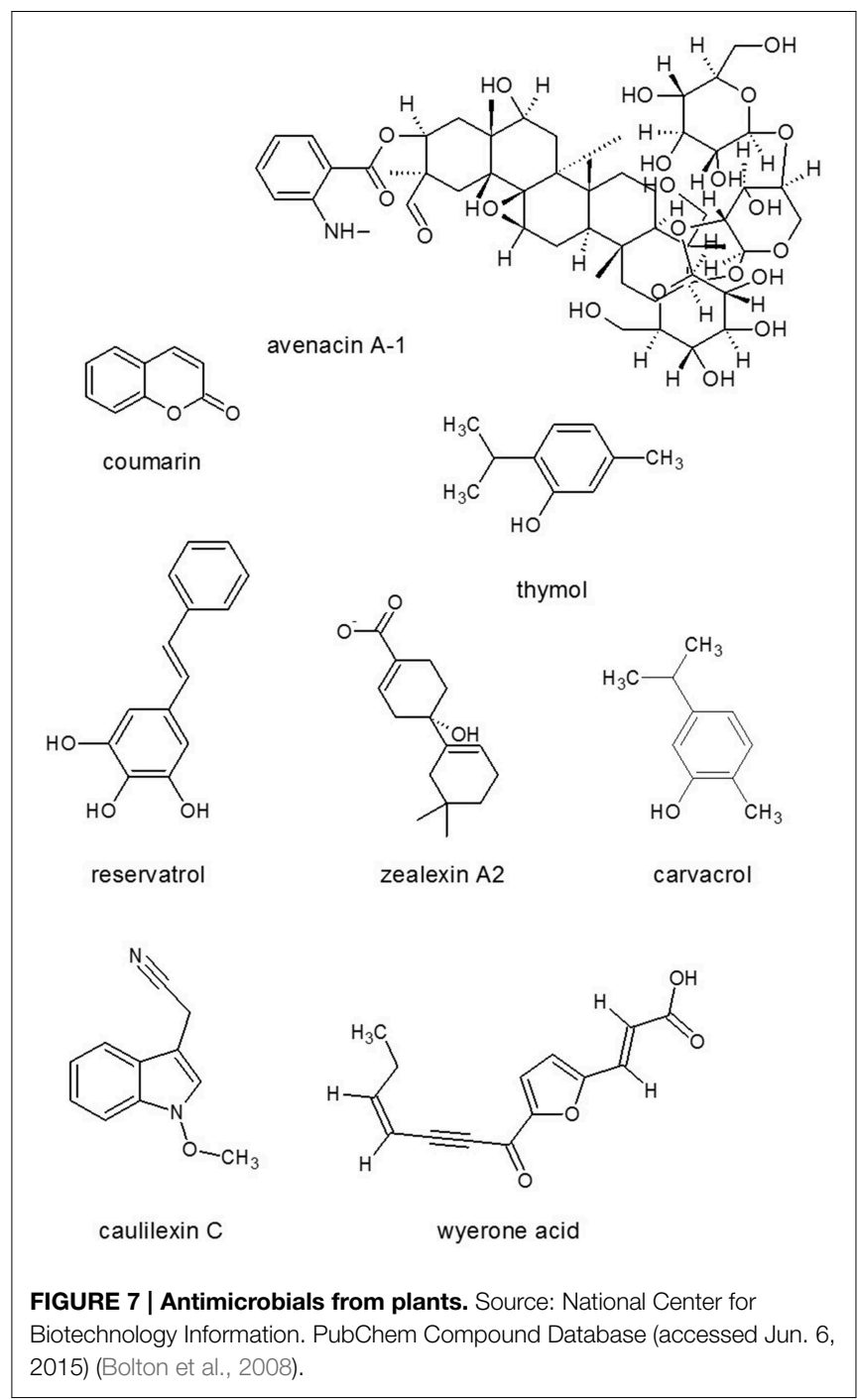

M. grisea and also by Colletotrichum lindemuthianum on artificial hydrophobic surfaces as well as on plant leaves (Stanley et al., 2002).

The two most effective inducers of the germination and appressorium formation were found to be 1,16-hexadecanedial and 1,16-hexadecanediol from cutin monomers in $M$. grisea (Gilbert et al., 1996). Besides cutin monomers, surface waxes also activated development processes in fungi (Liu et al., 2011). Appressorium formation was induced by leaf wax of rice or other plants or synthetic n-C22 fatty acid, fatty alcohol or alkane (Hegde and Kolattukudy, 1997). Selfinhibitors of the germination are related to phytotoxin pyriculol (Figure 9) (Kono et al., 1991). Moreover, other fungi can also produce specific, non-toxic inhibitors of conidial germination and appressorium formation of $M$. grisea like flaviolin, tenuazonic acid (Figure 2), and glisoprenins (Thines et al., 2004).

In the appressorium, several key biochemical and morphogenetic events take place under the generation of turgor pressure which, in M. grisea, is the highest pressure 
<smiles>C=C[C@]1(C)C=C2[C@@H](O)C[C@H]3[C@H](CCC(=O)C3(C)C)[C@@]2(C)CC1</smiles><smiles>C=C[C@]1(C)C=C2C(=O)C[C@H]3[C@@H](CCC(=O)C3(C)C)[C@@]2(C)CC1</smiles>
oryzalexin B<smiles>C=C[C@]1(C)C=C2[C@@H](O)C[C@]3(C)C(C)(C)[C@H](O)CC[C@]3(C)[C@H]2[C@H]1C</smiles>

oryzalexin D<smiles>C=C[C@]1(C)CC[C@H]2C(=C[C@H]3OC(=O)[C@@]4(C)C(=O)CC[C@]3(C)[C@@H]24)C1</smiles><smiles>C=C[C@]1(C)CC[C@@H]2COC3(O)OC[C@@H]4[C@@H](C=C2C1)OC(=O)[C@]43C</smiles>

momilactone $\mathrm{A}$

momilactone B<smiles>COc1cc(O)c2c(c1)O[C@H](c1ccc(O)cc1)CC2=O</smiles>

sakuranetin

FIGURE 8 | Structures of some phytoalexins isolated from rice. Source: National Center for Biotechnology Information. PubChem Compound Database (accessed Jun. 6, 2015) (Bolton et al., 2008).

recorded in any living cell at up to $8 \mathrm{MPa}$ to penetrate the tough rice cuticle (Howard et al., 1991). This exceptionally high pressure and mechanical penetration question the role of secreted cell wall-degrading enzymes in the first steps of invasion at least on the natural host (Howard and Valent, 1996). In order to generate the high turgor pressure, a thick melanin layer is deposited outside the primary cell wall. Several natural products inhibit melanin biosynthesis in a similarly specific and non-toxic manner, presumably hitting the same targets (Thines et al., 1995). Typical examples are coumarin (Figure 7), a common SM from plants (Wheeler and Bell, 1988), scytalol D from fungus Scytalidium sp. (Thines et al., 1998) and lipid biosynthesis inhibitor cerulenin (Figure 5) originally obtained from an isolate called Cephalosporium caerulens (Ohtake et al., 1999) that conspecific to Sarocladium oryzae phytopathogenic fungus of rice (Bills et al., 2004).

The first identified rice phytoalexins (reviewed by Peters, 2006) were the momilactones A and B (Figure 8) (Cartwright et al., 1981). Momilactones exhibit antifungal activity against $M$. grisea and only appear in rice leaves after infection (Kodama et al.,

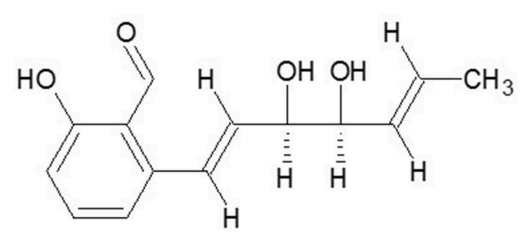

pyriculol

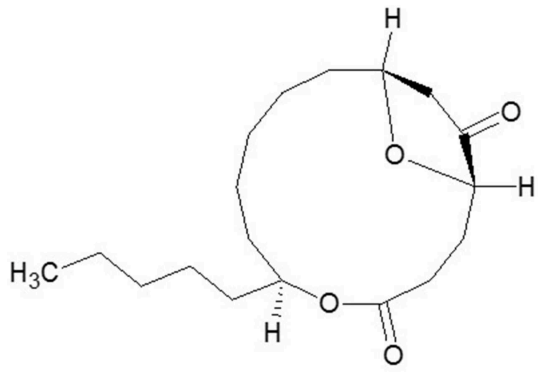

gloeosporon<smiles>O=C(O)/C=C/c1ccc(OS)cc1</smiles>

zosteric acid

FIGURE 9 | Autoinhibitor signal molecules responsible for inhibition of conidia germination. Phytotoxin pyriculol and gloeosporone, and/or appressorium formation: zosteric acid. Source: National Center for Biotechnology Information. PubChem Compound Database (accessed Jun. 6, 2015) (Bolton et al., 2008).

1988). These compounds were originally isolated and identified as plant growth inhibitors from rice seed (Kato-Noguchi et al., 2002). Another group of diterpenoid phytoalexins are oryzalexins (A-F) also isolated from rice (Akatsuka et al., 1985; Kato et al., 1993, 1994). Oryzalexins B, C and D (Figure 8) were identified as ent-pimarane diterpenoids, and found in $M$. grisea infected, but not healthy rice leaves (Akatsuka et al., 1985). Oryzalexin S (Tamogani et al., 1993), and phytocassanes A (Figure 8) to E (Koga et al., 1995, 1997) are also labdane-related diterpenoid phytoalexins in rice. Overexpression of another rice flavonon phytoalexin sakuranetin (Figure 8) resulted in an increased resistance to M. grisea (Kodama et al., 1992; Kim et al., 2009).

\section{Genus Colletotrichum}

Colletotrichum usually shares similar lifestyles and infection strategies with M. grisea, particularly during the early stages of pathogenesis. However, in hemibiotrophic C. gloeosporioides and in other Colletotrichum species unlike in the case of M. grisea, blocking the cell cycle did not prevent spore germination and appressoria formation (Nesher et al., 2008). The differentiation of infection structures including appressoria preceded mitosis and could proceed without nuclear division. Spore cell death did not occur during plant infection and the fungus primary 
infection structures remained viable throughout the infection cycle (Nesher et al., 2008).

The spores of many phytopathogenic fungi contain potent autoinhibitors, which prevent germination until they have been washed or diluted out of the spore. Colletotrichum spp. appeared to be a rich source of germination autoinhibitors. The first self-inhibitor to be isolated from conidia of C. gloeosporioides was gloeosporone (Figure 9) (Meyer et al., 1983) followed by (Z)- (E)-ethylidene-1,3-dihydroindole-2-one that were active at lower concentrations than gloeosporone (Tsurushima et al., 1995). At higher concentrations, the latter two compounds also inhibited the germination of conidia of other Colletotrichum spp. and of F. oxysporum (Tsurushima et al., 1995). Mycosporinalanine is also a potent autoinhibitor of conidial germination in C. graminicola that was synthesized during the development of conidia in the pycnidium, and it was quite effective in preventing germination of the spores until they have become dispersed (Leite and Nicholson, 1992). Interestingly, the synthesis of mycosporines and mycosporine-like amino acids occurs in fungi, bacteria, cyanobacteria, phytoplankton and macroalgae but not in animals because it needs the shikimate pathway (Sinha et al., 2007). Conidia germination is induced by ET in ripened fruits (Flaishman and Kolattukudy, 1994), additionally, by fatty alcohols from cuticular waxes (Podila et al., 1993; Hwang and Kolattukudy, 1995).

\section{Botrytis Cinerea}

The gray mold fungus $B$. cinerea is a typical necrotrophic phytopathogenic fungus with a very wide host range. It causes vast economic damage pre- and postharvesting (Amselem et al., 2011). Two groups of its phytotoxic metabolites have been characterized, the sesquiterpene botrydial (Figure 5) and related compounds (Colmenares et al., 2002) and botcinic acid and its derivatives (Tani et al., 2006). The sesquiterpene-derived phytotoxin botrydial has been implicated in virulence, as it can be detected in planta and its addition facilitates fungal penetration and colonization of plants (Deighton et al., 2001). In addition to SM toxins, ROS play in important role in B. cinerea as the fungus actively contributes to the elevated levels of ROS detected at infection sites and causing an oxidative burst during cuticle penetration and lesion formation (Tiedemann, 1997; Tudzynski and Kokkelink, 2009).

After fungal attack of grapevine and berries, leaves produced phytoalexins such as resveratrol (trans-3,5, $4^{\prime}$-trihydroxystilbene) (Figure 7) (Langcake and Pryce, 1976) and related compounds, which have antifungal activity toward $B$. cinerea and also a number of other fungal pathogens including Rhizopus stolonifer and Plasmopara viticola (Jeandet et al., 2002). Strong antifungal activity of carvacrol (Figure 7) and thymol (Figure 7) was also confirmed against $B$. cinerea and $R$. solani, Fusarium moniliforme and S. sclerotiorum (Mueller-Riebau et al., 1995; Tsao and Zhou, 2000; Camele et al., 2012). High inhibitory activity was detected against $B$. cinerea by monoterpene $\gamma$-terpinene (Espinosa-García and Langenheim, 1991), while monoterpene citral has been reported as a potent antimicrobial compound against B. cinerea (Tsao and Zhou, 2000) and Penicillium italicum (Saddiq and Khayyat, 2010). Essential plant oils (e.g., $D$-limonene, cineole, $\beta$-myrcene, $\alpha$-pinene, $\beta$-pinene, and camphor) showed remarkably high antifungal activity against B. cinerea (Wilson et al., 1997). In Vicia faba tissues, lowmolecular-weight phytoalexins such as wyerone acid (Figure 7) and wyerone furanoacetylenic were produced as part of the postinfection defense response against fungal pathogens. Wyerone acid accumulated in B. cinerea lesions, whereas in Botrytis fabae lesions the phytoalexin started to accumulate but later tended to decrease. The enhanced ability of $B$. fabae to colonize e.g., broad bean tissues seemed to be related to its capacity to detoxify broad bean phytoalexins (Buzi et al., 2003).

\section{Fusaria}

The filamentous fungus F. graminearum (teleomorph: Gibberella $z e a e$ ) is a worldwide pathogen of maize and small grains such as wheat, barley and oats. In infected grains, $F$. graminearum can produce several mycotoxins, including trichothecene derivatives (e.g., DON), polyketide zearalenone (ZEA), fusarin C (Figure 3) (Desjardins et al., 1993; Kimura et al., 2007) among which trichothecenes were related to the pathogenicity of $F$. graminearum (Gaffoor and Trail, 2006; Foroud and Eudes, 2009) reducing crop yield and quality. In plants, trichothecenes produced by Fusarium spp. cause necrosis, chlorosis, and mortality enabling them to mediate a wide variety of plant diseases, including wilts, stalk rot, root rot, and leaf rot in many important crop and ornamental plants (Abbas et al., 2013).

F. verticillioides (teleomorph: Gibberella moniliformis) is a ubiquitous pathogen of maize, attacking stalks, kernels, and seedlings. Considering the maize developmental stages, silking (R1), blister (R2), milk (R3), dough (R4), dent (R5), and physiological maturity (R6), infecting the seed at stages R2R5 with F. verticillioides revealed that the pathogen colonized seeds equally well (Bluhm and Woloshuk, 2005). Nevertheless, significant sphingoid-derived fumonisin B1 (FB1) mycotoxin (Figure 3) production (Abbas et al., 1994; Bluhm and Woloshuk, 2005; Picot et al., 2011) occurred only in the R5 (dent)-stage kernels where the R5 kernel acidic state also induced more FB1 production (Picot et al., 2011). Expression of FUM8 and FUM12 fumonisin biosynthetic genes as well as low amounts of FB1 was detected in the R3 (milk) and R4 (dough) stages. In contrast, no FB1 or FUM gene expression was detectable in the R2 (blister) stage. Other experiments revealed that the fungus produced fourfold more FB1 on maize polysaccharide amylopectin than on glucose carbon source (Bluhm and Woloshuk, 2005; Picot et al., 2011).

Usually extracellular ATP functions as an endogenous external metabolite regulating plant cell viability. FB1 toxin could trigger the depletion of extracellular ATP, which altered the abundance of particular intracellular plant proteins and ended in cell death, which process was reversible by exogenous ATP (Chivasa et al., 2005). Nevertheless, FB1 did not appear to be a primary virulence factor, while DON (Figure 3) was considered to have a key role as a virulence factor at least in F. graminearum, and their induction is quite different. The production of DON and the spread of the fungus in the spikes correlated well with the presence of several polyamine compounds that accumulate as the infection progresses through the spike (Gardiner et al., 2010). 
SM culmorins are tricyclic sesquiterpene diols that have been reported from F. culmorum, F. graminearum and F. venenatum (Langseth et al., 2001). Culmorin had weak phytotoxicity to wheat coleoptile tissue (Wang and Miller, 1988), but its role in wheat head scab was not reported. Contaminated grain samples are usually not screened for culmorins, because there are no limits for these SMs. However, culmorin and hydroxyculmorins were detected at relatively high levels in naturally contaminated Norwegian wheat, barley, and oat samples co-occurring with high DON concentrations (Ghebremeskel and Langseth, 2001).

Inhibition of toxigenesis in Fusaria has also been studied. Velluti et al. (2004) explored the efficacy of cinnamon, clove, lemongrass, oregano and palmarosa essential oils in order to prevent ZEA and DON accumulation when inoculated with $F$. graminearum; however, it should be noted that this assay was based on non-sterilized, naturally contaminated maize grain. Dambolena et al. (2011) studied the capacity of 10 natural phenolic compounds to inhibit FB1 synthesis by $F$. verticillioides and revealed that thymol, carvacrol (Figure 7), isoeugenol as well as eugenol were the most active. The plant phenol chlorophorin was also effective in reducing FB1 toxin production (94\% reduction), followed by caffeic acid (hydroxycinnamic acid), ferulic acid, vanillic acid and iroko (Beekrum et al., 2003). In F. proliferatum, aquaeous extracts of host plants inhibited the fungal growth in dose dependent manner, resulting in growth induction at low doses. While, pea extract inhibited the FB production in most of the strains (Stępień et al., 2015).

Modulation of spore germination is also often based on lowmolecular weight substances produced by the plant host. For example, flavonoids stimulated the germination of conidia of $F$. solani on the leaves of vegetables (Ruan et al., 1995). Moreover, Garcia et al. (2012) found that production of FB1 and FB2 by $F$. verticillioides, and ZEA and DON by F. graminearum was stimulated or similar to the controls in most of the conditions tested using Equisetum arvense and Stevia rebaudiana extracts.

\section{Aspergilli}

Aspergillus species can be saprophytic, or symptomless endophytes or weak and opportunistic plant pathogen. A. flavus from yellow Aspergilli is a weak and opportunistic plant pathogen. It lacks host specificity (St Leger et al., 2000) as it can attack seeds of both monocots and dicots such as maize, cotton, groundnuts (peanuts) and other nuts like tree nuts such as Brazil nuts, pecans, pistachio nuts, and walnuts. A. flavus can cause ear rot on maize and preharvest contamination of these crops with SM AFs is common, but A. flavus also causes the spoilage of post-harvest grains during storage resulting in significant economic losses to farmers (Figure 10).

A. flavus, A. parasiticus and A. nidulans are proposed to derive acetyl CoA for the biosynthesis of SM toxins (i.e., sterigmatocystin and AF) (Figure 5) from fatty acids present in the kernel of maize (Howlett, 2006). In vitro supplemented oleic acid induced the biogenesis of fungal peroxisomes, as well as catalase activity and $\beta$-oxidation. Concomitantly with the increased expression of biosynthetic genes for precursor sterigmatocystin and AF in hyphae, colonizing the embryo and aleuronic layer, where most seed lipids are stored, AF precursor norsolorinic acid accumulated in peroxisomes (Maggio-Hall et al., 2005).

Bagheri-Gavkosh et al. (2009) showed that AF B1 production by $A$. parasiticus was inhibited by methanolic extracts of Ephedra major aerial parts and roots, whereas the essential oil of the plant aerial parts did not exhibit any effect on AF B1 biosynthesis. The authors attributed the inhibition of $A$. parasiticus growth and AF $B 1$ production to the presence of flavonoid compounds such as p-coumaric acid and quercetin in plant extracts. Dos Santos and Furlong (2008) noted that AF B1 and AF B2 production by A. flavus was inhibited in the presence of methanolic extracts from banana pulp and peel, orange, eggplant and potato pulp. However, these authors found that in the presence of banana pulp and potato pulp extracts, A. flavus produced AF B2, which was not detected in the control. Crude essential oil of Betula alba also inhibited both AF production and fungal growth in parallel. Jermnak et al. (2012) found that after roughly purifying the oil by silica gel column chromatography an active fraction was obtained that was identified as methyl syringate. This compound strongly inhibited norsolorinic acid production, an early step of the AF biosynthetic pathway: it inhibited the AF B1 and AF G1 production of $A$. parasiticus in liquid medium in a dosedependent manner and also inhibited AF B1 production by $A$. flavus on raw peanuts.

Black aspergilli are common soil organisms decomposing dead plant residues, some of them are capable of a biotrophic endophytic existence with maize and onion. A. niger var. niger and A. carbonarius black Aspergilli are the two major producers of ochratoxin A (Figure 4) that is nephrotoxic, teratogenic, carcinogenic, and immunosuppressive in animals, and of FB1 mycotoxin (Palencia et al., 2010).

In A. terreus infection, crops such as wheat, ryegrass and potatoes were shown to acquire disease. A number of SMs and mycotoxins, including territrem A, citreoviridin, citrinin, gliotoxin (Figure 4), patulin, terrein, terreic acid, and terretonin are coded in A. terreus (Guo and Wang, 2014). The phytotoxic SM terrein possessed ecological, antimicrobial, antiproliferative, and antioxidative activities was also highly induced in plantderived media and in induced lesions on fruit surfaces (Zaehle et al., 2014).

\section{Rhizoctonia Solani Species Complex}

The soil-borne fungus Rhizoctonia solani (teleomorph Thanatephorus cucumeris), belonging to the phylum Basidiomycota, is an economically important plant pathogen. $R$. solani, as a non-obligate necrotrophic pathogen, causes diseases in many crops including species in the families Solanaceae, Fabaceae, Asteraceae, Poaceae, and Brassicaceae as well as ornamental plants and forest trees throughout the world (Gonzalez Garcia et al., 2006). The anamorph $R$. solani is a species complex and consists species of at least 14 different, genetically isolated populations [=anastomosis groups (AG)] that differ in their ecology and host range (Carling et al., 2002; Stodart et al., 2007).

Recently it was considered that $R$. solani synthesizes HSTs and NHSTs (Vidhyasekaran et al., 1997). HSTs from R. solani could 


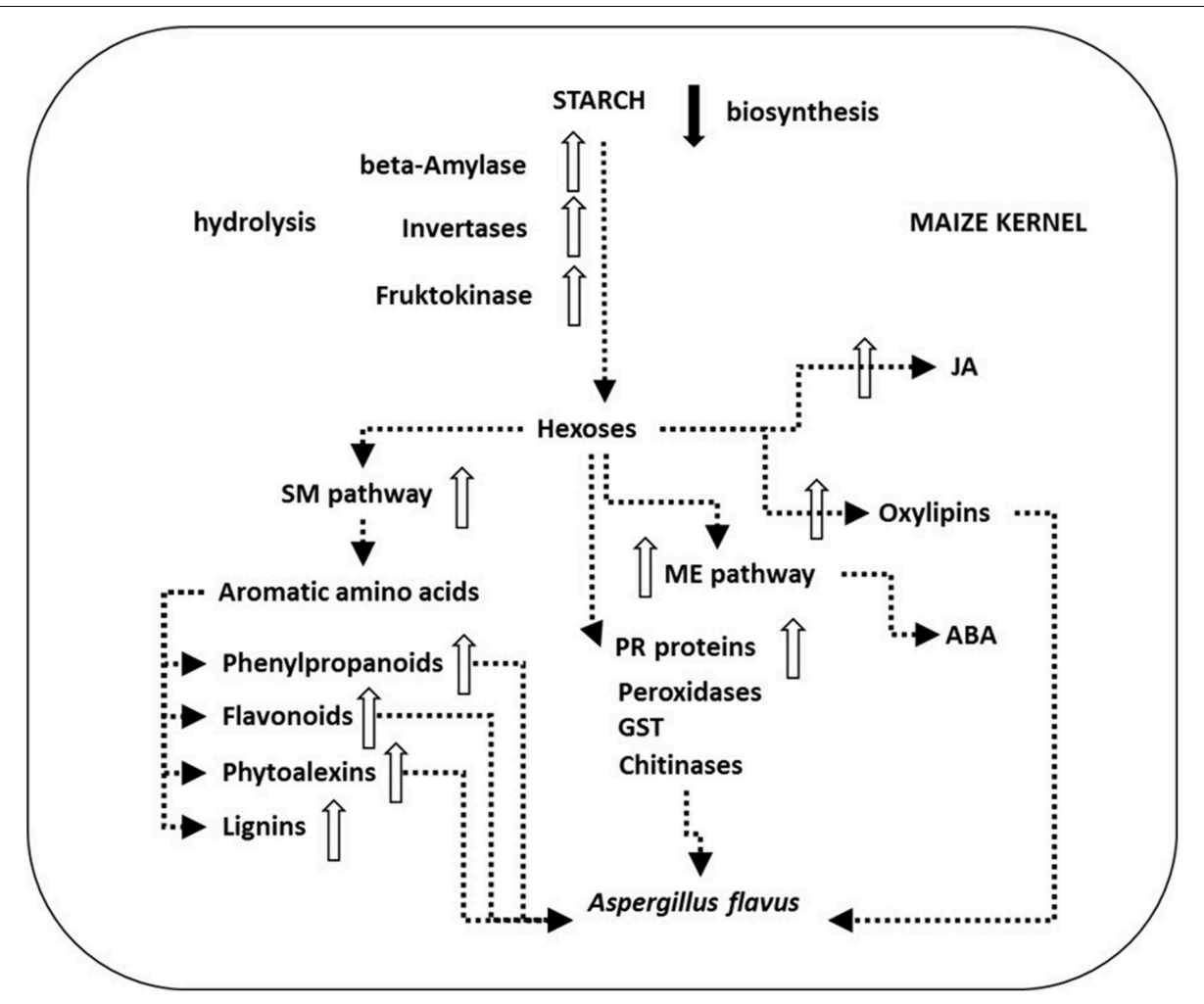

FIGURE 10 | Schematic presentation of main plant defense processes in Aspergillus flavus-maize interactions. A. flavus can attack kernels during all the six stages of their development. However, infection in non-injured kernels takes place later in the field, during the dent (R5) developmental stage just prior to physiological maturity (R6) (Marsh and Payne, 1984). As soon as 4 days after inoculation A. flavus mycelium reaches the aleurone, endosperm and germ tissue (Dolezal et al., 2013). Transcriptional analysis of the maize-A. flavus pathogen interaction revealed down-regulated (black arrow) starch biosynthesis and up-regulated genes (white arrows) of plant starch hydrolytic enzymes like $\beta$-amylase as well as downstream invertases and fructokinase. The produced hexoses flow through the up-regulated shikimate (SM) pathway, the methylerithryole (ME) pathway and toward up-regulated jasmonic acid (JA) and oxylipin biosynthesis, and feed pathogenesis related (PR) protein synthesis, e.g., peroxidases, glutathione S-transferase (GST) or chitinases that were also found up-regulated during infection. Oxylipins up-regulate aflatoxin (AF) biosynthesis and sexual reproduction in $A$. flavus and down-regulate fungal growth. Up-regulation of the SM pathway leads to the production of antifungal compounds flavonoids, phenylpropanoids, phytoalexins, and up-regulated lignin production in maize. Up-regulated plant hormone JA and abscisic acid (ABA) production is crucial in these defense mechanisms (Dolezal et al., 2014). increase the virulence of the pathogen (e.g., HC-toxin on maize) (Brooks, 2007), and were often pathogenicity determinants required for a pathogen to incite disease (reviewed in Wolpert et al., 2002). For example, significantly increased five new superoxide dismutase (SOD) activities were detected in plant under treatment of rice leaf sheaths with $R$. solani-toxin, which eliminated the antifungal oxidative burst (Paranidharan et al., 2005).

Previous research has shown that $R$. solani also produces phenyl acetic acid and its derivatives (Bartz et al., 2013), a phenolic compound, and a carbohydrate as phytotoxins that supported the broad host range and diversity within the $R$. solani species. Xu et al. (2015) identified eight compounds from fermentation broth of $R$. solani, from which $m$-hydroxymethylphenyl pentanoate, (Z)-3-methylpent-2-en1,5-dioic acid and 3-methoxyfuran-2-carboxylic acid showed phytotoxicity in vitro.

Interestingly, in the $R$. solani AG1-IA genome project, genes homologous to reported mycotoxin biosynthesis genes could not be identified (Zheng et al., 2013). However, genes for a putative phytotoxin enniatin (Figure 4) and sequences featuring homology to putative trichothecene citrinin, and AF (Figure 4) and terpene biosynthesis genes (e.g., genes encoding sesquiterpene synthases) were identified. In addition, three volvatoxin genes that homologous to volvatoxin from Volvariella volvacea (Basidiomycota) were also detected (Wibberg et al., 2014). In proteome analysis, a trichothecene 3-Oacetyltransferase that is required for trichothecene biosynthesis and is involved in reducing the toxicity of trichothecene mycotoxin DON of Fusaria (Audenaert et al., 2014), was differentially expressed during the development stage in $R$. solani AG1 (Kwon et al., 2014).

In the last decade, newly related chemical structures have been reported to have significant antifungal activity against R. solani: arvelexin isolated from Thlaspi arvense (stinkweed) (Pedras et al., 2003), isalexin, brassicanate A and rutalexin from Brassica napus, ssp. rapifera (Pedras et al., 2004). Cauliflower (Brassica oleracea var. botrytis) produced other phytoalexins 
caulilexins A, B, and C (Figure 7), which were also active against the economically important pathogenic fungi Leptosphaeria maculans and S. sclerotiorum (Pedras et al., 2006). Pedras and Ahiahonu (2005) reviewed the detoxification metabolism of phytoalexins in phytopathogenic fungi. Indole-3-acetaldoxime is an intermediate in the biosynthesis of diverse plant SMs such as indole-3-acetonitrile, brassinin, and brassilexin, as well as the indole glucosinolate (glucobrassicin) and the plant hormone IAA (Figure 1) in Cruciferae. Metabolism of indole-3-acetaldoxime to IAA via indole-3-acetonitrile by fungi could support the development of plant diseases in crucifers (Pedras and Montaut, 2003).

\section{Genus Cochliobolus}

The filamentous ascomycete genus Cochliobolus (anamorph Bipolaris/Curvularia; Manamgoda et al., 2014) is composed of more than 40 closely related pathogenic species with particular specificity to their host plants (Condon et al., 2013). Gao et al. (2014) reported the genome sequence of a highly virulent $C$. lunatus strain, and phylogenomic analysis indicated that $C$. lunatus was evolved from C. heterostrophus. C. lunatus CX-3 strain was capable of producing diverse SMs (Table 1) such as NHSTs and melanin that could aid in niche exploitation and pathogenicity.

It was known previously that the ability to produce HST T-toxin requires three genes encoded at two unlinked loci (Baker et al., 2006). However, Inderbitzin et al. (2010) reported further six genes including two PKSs, one decarboxylase, five dehydrogenases, and one unknown protein that were involved in T-toxin production and high virulence of C. heterostrophus to maize. HST1, one NPRS of C. carbonum (Bipolaris zeicola) played a key role in the cyclic tetrapeptide HC-toxin (Figure 2) biosynthesis (Walton, 2006), which was also produced by Alternaria jesenskae (Wight et al., 2013) and was also encoded in another maize pathogen Setosphaeria turcica (Condon et al., 2013). Six other known PKSs were found to be involved in different kinds of toxin biosynthesis such as A. alternata ACTtoxin, F. graminearum ZEA, F. verticilloides fumonisin, A. ochraceus OTA and C. heterostrophus T-toxin. Phylogenetic and modular analyses suggested that the protein structures of $C$. lunatus CX-3 NRPSs were obviously different from other known NRPSs being involved in the biosynthesis of mycotoxins such as HC-toxin (Figure 2) of C. carbonum, similarly to AM-toxin (Figure 2) of A. alternata, gliotoxin (Figure 4) of A. fumigatus and enniatin of F. equiseti (Gao et al., 2014).

\section{Genus Alternaria}

Alternaria species have different lifestyles ranging from saprophytes to endophytes and to pathogens. Phylogenetic relations of the Alternaria complex was revisited and delineated by Woudenberg et al. (2013) within Alternaria and related genera based on nucleotide sequence data. A. alternata has the ability to produce more than $60 \mathrm{SMs}$ from which at least $10 \mathrm{PKS}$ products can be found (Saha et al., 2012) (Table 1). Alternaria species have been reported to cause diseases in nearly 400 plant species including a wide variety of economically important crops and cause severe economic problems. A. alternata alone can infect more than 100 plant species (Thomma, 2003). The production of diverse phytotoxins and HSTs can be considered as a key reason for the success of these pathogens (Nishimura and Kohmoto, 1983). From about 20 HSTs that have been documented (Otani et al., 1995; Walton, 1996), at least seven are from A. alternata pathotypes (Otani et al., 1995). For HST ACR-toxin production and pathogenicity, PKS gene ACRTS2 was found to be essential of the rough lemon pathotype of A. alternata (Izumi et al., 2012). Several NHSTs are also produced in Alternaria such as brefeldin A, altertoxin, and tentoxin (Figure 2) and also other mycotoxins. Alternariol (Figure 2) and alternariol-9-methyl ether are major NHSTs that are common contaminants of food such as cereals, fruits and fruit juices (Scott, 2001). A PKS involved in melanin biosynthesis was also characterized and named ALM (albino) (Kimura and Tsuge, 1993). For production of SM siderophores and virulence, the $A$. alternata gene AaNPS6, encoding a polypeptide analogous to fungal NRPS was demonstrated by Chen et al. (2013). The Alternaria toxins provide prospect for biocontrol of weeds due to high phytotoxic effect against weeds but low mammalian toxicity (Abbas et al., 1995; Chen et al., 2005; Evidente et al., 2009; Yang et al., 2012).

From the plant side, high concentrations of alkaloid phytoalexin camalexin (Tsuji et al., 1992) have been observed at the infection site of A. alternata (Schuhegger et al., 2007) and also in the proximity to the lesions induced by Botrytis species (Kliebenstein et al., 2005). In A. thaliana leaves both biotrophic and necrotrophic plant pathogens induced camalexin formation (Thomma et al., 1999). A. brassicicola could detoxify camalexin but at much slower rate than phytoalexin brassinin from Brassicaceae (Pedras et al., 2014).

\section{Secondary Metabolite Production of Biotrophs}

Growth and reproduction of obligate biotrophic phytopathogens that are very poor in SM production like powdery mildews are entirely dependent on living plant cells. Spanu et al. (2010) hypothesized that Blumeria synthesized only one iron siderophore and one simple polyketide pigment of the cleistothecia. Similar trends have been observed in other biotrophs, such as the basidiomycete corn smut fungus Ustilago maydis and the plant symbiotic fungus Tuber melanosporum.

Cladosporium fulvum (Passalora fulva) is also a biotrophic fungus that infecting tomato, grows extracellularly in close contact with host mesophyll cells. The only known SMs produced by C. fulvum is cladofulvin (de Wit et al., 2012; Collemare et al., 2014) anthraquinone pigment. However, cladofulvin has not been detected to cause necrosis on Solanaceae plants or to show any antimicrobial activity (Collemare et al., 2014). C. fulvum has also the potential to produce elsinochrome and cercosporin toxins, but the corresponding core genes were not expressed during infection of tomato (Collemare et al., 2014). It has been suggested that loss of SM biosynthetic pathways is associated with biotrophy (Spanu et al., 2010); nevertheless, the biotrophic C. fulvum has twice the number of key SM genes compared to the closely related hemibiotrophic Dothistroma septosporum (teleomorph Mycosphaerella pini), of which 14 and 9, respectively, are organized into gene clusters along with other SM-related genes (de Wit et al., 2012). The numbers of its 
SM enzyme-encoding genes were comparable to those of $M$. graminicola, but were lower than those in most other sequenced Dothideomycete (Table 1). It could be concluded that, in contrast to reduced SM production capacity, down-regulation of high number of SM biosynthetic pathways might represent another mechanism associated with a biotrophic lifestyle (Collemare et al., 2014).

\section{Conclusions and Future Aspects}

Fungal-plant host interactions represent biochemically complex and challenging scenarios that are being investigated also by metabolomic approaches (Allwood et al., 2008). It is noteworthy that although SMs play important roles in the virulence and lifestyle of fungal plant pathogens only about $25 \%$ of the fungal SM gene clusters have already been characterized functionally and this number is much lower at plant side.

Concomitantly, comparative genomics and transcriptomics are employed to obtain insights into the genetic features that enable fungal pathogens to adapt successfully to various ecological niches and to adopt different pathogenic lifestyles. The suites of fungal SM genes reflect astounding diversity among species, hinting that gene products, particularly those associated with unique genomic regions, are candidates for pathogenic lifestyle differences. Furthermore, horizontal gene and chromosome transfers provide a means for pathogens to broaden their host range (Mehrabi et al., 2011; Fitzpatrick, 2012). The increasing availability of fungal pathogen genome sequences and next-generation genomic tools allow us to survey the SM gene clusters in individual fungi. The recent availability

\section{References}

Abbas, H. K., Tanaka, T., Duke, S. O., Porter, J. K., Wray, E. M., Hodges, L., et al. (1994). Fumonisin- and AAL-toxin-induced disruption of sphingolipid metabolism with accumulation of free sphingoid bases. Plant Physiol. 106, 1085-1093.

Abbas, H. K., Tanaka, T., and Shier, W. T. (1995). Biological activities of synthetic analogues of Alternaria alternata toxin (AAL-toxin) and fumonisin in plant and mammalian cell cultures. Phytochemistry 40, 1681-1689.

Abbas, H. K., Yoshizawa, T., and Shier, W. T. (2013). Cytotoxicity and phytotoxicity of trichothecene mycotoxins produced by Fusarium spp. Toxicon 74, 68-75. doi: 10.1016/j.toxicon.2013.07.026

Affeldt, K. J., Brodhagen, M., and Keller, N. P. (2012). Aspergillus oxylipin signaling and quorum sensing pathways depend on $\mathrm{G}$ protein-coupled receptors. Toxins (Basel.) 4, 695-717. doi: 10.3390/toxins4090695

Ahuja, I., Kissen, R., and Bones, A. M. (2012). Phytoalexins in defense against pathogens. Trends Plant Sci. 17, 73-90. doi: 10.1016/j.tplants.2011. 11.002

Akatsuka, T., Kodama, O., Sekido, H., Kono, Y., and Takeuchi, S. (1985). Novel phytoalexins (oryzalexins A, B and C) isolated from rice blast leaves infected with Pyricularia oryzae. Agric. Biol. Chem. 49, 1689-1701. doi: 10.1080/00021369.1985.10866951

Allwood, J. W., Ellis, D. I., and Goodacre, R. (2008). Metabolomic technologies and their application to the study of plants and plant-host interactions. Physiol. Plant. 132, 117-1135. doi: 10.1111/j.1399-3054.2007.01001.x

Amagasa, T., Paul, R. N., Heitholt, J. J., and Duke, S. O. (1994). Physiological effects of cornexistin on Lemna pausicostata. Pestic. Biochem. Physiol. 49, 37-52. doi: $10.1006 /$ pest. 1994.1032 of next-generation RNA-Seq technologies has revolutionized transcriptomic profiling and are used to probe the expression of SM gene clusters during various stages of infection. Unlike microarray, RNA-Seq allows the simultaneous quantification of transcripts from more than one organism and is thus perfectly suited for the study of plant-pathogen interactions (Chooi and Solomon, 2014). Moreover, manipulations of strain-unique SM genes associated with host-specific virulence provide possibility to investigate fungal-plant interaction.

The great structural diversity of phytotoxins, the high potency and exclusive mechanisms of action (compared to synthetic herbicides) make fungal toxins highly attractive for discovering herbicidal activity. Even if natural phytotoxins are not necessarily suitable for direct use as a commercial herbicide, the identification of mechanisms are very important for new herbicide developments. Newly developed herbicides with environmentally friendly component could be used more safely in integrated pest management systems. On the other side, plant SMs can be used against plant pathogens (especially in sprayable forms) as natural plant extracts for example in organic agricultural production systems. Deeper knowledge of the fungus-plant interaction may help resistance breeding of new plant cultivars/hybrids against stresses such as abiotic (e.g., heat) stress or against fungal diseases.

\section{Acknowledgments}

This work was supported by the Hungarian Scientific Research Fund (OTKA K100464 and OTKA K108333).
Amare, M. G., and Keller, N. P. (2014). Molecular mechanisms of Aspergillus flavus secondary metabolism and development. Fungal Genet. Biol. 66, 11-18. doi: 10.1016/j.fgb.2014.02.008

Amselem, J., Cuomo, C. A., van Kan, J. A. L., Viaud, M., Benito, E. P., Couloux, A., et al. (2011). Genomic analysis of the necrotrophic fungal pathogens Sclerotinia sclerotiorum and Botrytis cinerea. PLoS Genet. 7:e1002230. doi: 10.1371/journal.pgen.1002230

Atkinson, P., and Blakeman, J. P. (1982). Seasonal occurrence of an antimicrobial flavanone, sakuranetin, associated with glands on leaves of Ribes nigrum. New Phytol. 92, 63-74. doi: 10.1111/j.1469-8137.1982.tb03363.x

Audenaert, K., Vanheule, A., Höfte, M., and Haesaert, G. (2014). Deoxynivalenol: a major player in the multifaceted response of Fusarium to its environment. Toxins (Basel.) 6, 1-19. doi: 10.3390/toxins6010001

Avalos, J., and Estrada, A. F. (2010). Regulation by light in Fusarium. Fungal Genet. Biol. 47, 930-938. doi: 10.1016/j.fgb.2010.05.001

Baetz, U., and Martinoia, E. (2014). Root exudates: the hidden part of plant defense. Trends Plant Sci. 19, 90-98. doi: 10.1016/j.tplants.2013.11.006

Bagheri-Gavkosh, S., Bigdeli, M., Shams-Ghahfarokhi, M., and RazzaghiAbyaneh, M. (2009). Inhibitory effects of Ephedra major host on Aspergillus parasiticus growth and aflatoxin production. Mycopathologia 168, 249-255. doi: 10.1007/s11046-009-9220-x

Baker, S. E., Kroken, S., Inderbitzin, P., Asvarak, T., Li, B. Y., Shi, L., et al. (2006). Two polyketide synthase-encoding genes are required for biosynthesis of the polyketide virulence factor, T-toxin, by Cochliobolus heterostrophus. Mol. Plant Microbe Interact. 19, 139-149. doi: 10.1094/MPMI-19-0139

Balasundram, N., Sundram, K., and Samman, S. (2006). Phenolic compounds in plants and agri-industrial by-products: antioxidant activity, occurrence, and potential uses. Food Chem. 99, 191-203. doi: 10.1016/j.foodchem.2005. 07.042 
Barna, B., Fodor, J., Harrach, B. D., Pogány, M., and Király, Z. (2012). The Janus face of reactive oxygen species in resistance and susceptibility of plants to necrotrophic and biotrophic pathogens. Plant Physiol. Biochem. 59, 37-43. doi: 10.1016/j.plaphy.2012.01.014

Bartz, F. E., Glassbrook, N. J., Danehower, D. A., and Cubeta, M. A. (2013). Modulation of the phenylacetic acid metabolic complex by quinic acid alters the disease-causing activity of Rhizoctonia solani on tomato. Phytochemistry 89, 47-52. doi: 10.1016/j.phytochem.2012.09.018

Bednarek, P., Kwon, C., and Schulze-Lefert, P. (2010). Not a peripheral issue: secretion in plant-microbe interactions. Curr. Opin. Plant Biol. 13, 378-387. doi: 10.1016/j.pbi.2010.05.002

Beekrum, S., Govinden, R., Padayachee, T., and Odhav, B. (2003). Naturally occurring phenols: a detoxification strategy for fumonisin B1. Food Addit. Contam. 20, 490-493. doi: 10.1080/0265203031000098678

Biemelt, S., and Sonnewald, U. (2006). Plant-microbe interactions to probe regulation of plant carbon metabolism. J. Plant Physiol. 163, 307-318. doi: 10.1016/j.jplph.2005.10.011

Bills, G. F., Platas, G., and Gams, W. (2004). Conspecificity of the cerulenin and helvolic acid producing "Cephalosporium caerulens," and the hypocrealean fungus Sarocladium oryzae. Mycol. Res. 108, 1291-1300. doi: $10.1017 /$ S0953756204001297

Bluhm, B. H., and Woloshuk, C. P. (2005). Amylopectin induces fumonisin B1 production by Fusarium verticillioides during colonization of maize kernels. Mol. Plant Microbe Interact. 18, 1333-1339. doi: 10.1094/MPMI-18-1333

Bohlmann, J., and Keeling, C. I. (2008). Terpenoid biomaterials. Plant J. 54, 656-669. doi: 10.1111/j.1365-313X.2008.03449.x

Bolton, E. E., Wang, Y., Thiessen, P. A., and Bryant, S. H. (2008). "PubChem: integrated platform of small molecules and biological activities," in Annual Reports in Computational Chemistry, eds R. A. Wheeler and D. C. Spellmeyer (Oxford: Elsevier), 217-241. doi: 10.1016/S1574-1400(08)00012-1

Bömke, C., and Tudzynski, B. (2009). Diversity, regulation, and evolution of the gibberellin biosynthetic pathway in fungi compared to plants and bacteria. Phytochemistry 70, 1876-1893. doi: 10.1016/j.phytochem.2009.05.020

Brodhagen, M., Tsitsigiannis, D. I., Hornung, E., Goebel, C., Feussner, I., and Keller, N. P. (2008). Reciprocal oxylipin-mediated cross-talk in the Aspergillus-seed pathosystem. Mol. Microbiol. 67, 378-391. doi: 10.1111/j.13652958.2007.06045.x

Brodhun, F., Cristobal-Sarramian, A., Zabel, S., Newie, J., Hamberg, M., and Feussner, I. (2013). An iron 13S-lipoxygenase with an $\alpha$-linolenic acid specific hydroperoxidase activity from Fusarium oxysporum. PLoS ONE 8:e64919. doi: 10.1371/journal.pone.0064919

Brooks, S. A. (2007). Sensitivity to a phytotoxin from Rhizoctonia solani correlates with sheath blight susceptibility in rice. Phytopathology 97, 1207-1212. doi: 10.1094/PHYTO-97-10-1207

Butchko, R. A. E., Brown, D. W., Busman, M., Tudzynski, B., and Wiemann, P. (2012). Lael regulates expression of multiple secondary metabolite gene clusters in Fusarium verticillioides. Fungal Genet. Biol. 49, 602-612. doi: 10.1016/j.fgb.2012.06.003

Buzi, A., Chilosi, G., Timperio, A. M., Zolla, L., Rossall, S., and Magro, P. (2003). Polygalacturonase produced by Botrytis fabae as elicitor of two furanoacetylenic phytoalexins in Vicia faba pods. J. Plant Pathol. 85, 111-116. doi: 10.4454/jpp.v85i2.1018

Calvo, A. M., Hinze, L. L., Gardner, H. W., and Keller, N. P. (1999). Sporogenic effect of polyunsaturated fatty acids on development of Aspergillus spp. Appl. Environ. Microbiol. 65, 3668-3673.

Camele, I., Altieri, L., De Martino, L., De Feo, V., Mancini, E., and Rana, G. L. (2012). In vitro control of post-harvest fruit rot fungi by some plant essential oil components. Int. J. Mol. Sci. 13, 2290-2300. doi: 10.3390/ijms13022290

Carling, D. E., Baird, R. E., Gitaitis, R. D., Brainard, K. A., and Kuninaga, S. (2002). Characterization of AG-13, a newly reported anastomosis group of Rhizoctonia solani. Phytopathology 92, 893-899. doi: 10.1094/PHYTO.2002.92.8.893

Cartwright, D. W., Langcake, P., Pryce, R. J., Leworthy, D. P., and Ride, J. P. (1981). Isolation and characterization of two phytoalexins from rice as momilactones A and B. Phytochemistry 20, 535-537. doi: 10.1016/S0031-9422(00)84189-8

Chen, L. H., Lin, C. H., and Chung, K. R. (2013). A nonribosomal peptide synthetase mediates siderophore production and virulence in the citrus fungal pathogen Alternaria alternata. Mol. Plant Pathol. 14, 497-505. doi: $10.1111 / \mathrm{mpp} .12021$
Chen, S., Dai, X., Qiang, S., and Tang, Y. (2005). Effect of a nonhost-selective toxin from Alternaria alternata on chloroplast-electron transfer activity in Eupatorium adenophorum. Plant Pathol. 54, 671-677. doi: 10.1111/j.13653059.2005.01249.x

Chivasa, S., Ndimba, B. K., Simon, W. J., Lindsey, K., and Slabas, A. R. (2005). Extracellular ATP functions as an endogenous external metabolite regulating plant cell viability. Plant Cell 17, 3019-3034. doi: 10.1105/tpc.105.036806

Chooi, Y. H., and Solomon, P. S. (2014). A chemical ecogenomics approach to understand the roles of secondary metabolites in fungal cereal pathogens. Front. Microbiol. 5:640. doi: 10.3389/fmicb.2014.00640

Collemare, J., Billard, A., Böhnert, H. U., and Lebrun, M.-H. (2008). Biosynthesis of secondary metabolites in the rice blast fungus Magnaporthe grisea: the role of hybrid PKS-NRPS in pathogenicity. Mycol. Res. 112, 207-215. doi: 10.1016/j.mycres.2007.08.003

Collemare, J., Griffiths, S., Iida, Y., Karimi Jashni, M., Battaglia, E., Cox, R. J., et al. (2014). Secondary metabolism and biotrophic lifestyle in the tomato pathogen Cladosporium fulvum. PLoS ONE 9:e85877. doi: 10.1371/journal.pone.0085877

Colmenares, A., Aleu, J., Durán-Patrón, R., Collado, I. G., and HernándezGalán, R. (2002). The putative role of botrydial and related metabolites in the infection mechanism of Botrytis cinerea. J. Chem. Ecol. 28, 997-1005. doi: 10.1023/A:1015209817830

Condon, B. J., Leng, Y., Wu, D., Bushley, K. E., Ohm, R. A., Otillar, R., et al. (2013). Comparative genome structure, secondary metabolite, and effector coding capacity across Cochliobolus pathogens. PLoS Genet. 9:e1003233. doi: 10.1371/journal.pgen.1003233

Couch, B. C., and Kohn, L. M. (2002). A multilocus gene genealogy concordant with host preference indicates segregation of a new species, Magnaporthe oryzae, from M. grisea. Mycologia 94, 683-693. doi: 10.2307/3761719

Crowley, D. E., and Kraemer, S. M. (2007). "Function of siderophores in the plant rhizosphere," in The Rhizosphere, Biochemistry and Organic Substances at the Soil-Plant Interface, eds R. Pinton, Z. Varanini, and P. Nannipieri (New York, NY: CRC Press), 73-109.

Crozier, A., Jaganath, I. B., and Clifford, M. N. (2008). "Phenols, poliphenols and tannins: an overview," in Plant Secondary Metabolites: Occurrence, Structure and Role in the Human Diet, eds A. Crozier, M. N. Clifford, and H. Ashihara (Oxford, UK: Blackwell Publishing Ltd), 1-24.

Dakora, F., and Phillips, D. (2002). Root exudates as mediators of mineral acquisition in low-nutrient environments. Plant Soil 245, 35-47.

Dambolena, J. S., Zygadlo, J. A., and Rubinstein, H. R. (2011). Antifumonisin activity of natural phenolic compounds A structure-propertyactivity relationship study. Int. J. Food Microbiol. 145, 140-146. doi: 10.1016/j.ijfoodmicro.2010.12.001

Deighton, N., Muckenschnabel, I., Colmenares, A. J., Collado, I. G., and Williamson, B. (2001). Botrydial is produced in plant tissues infected by Botrytis cinerea. Phytochemistry 57, 689-692. doi: 10.1016/S0031-9422(01) 00088-7

Deller, S., Hammond-Kosack, K. E., and Rudd, J. J. (2011). The complex interactions between host immunity and non-biotrophic fungal pathogens of wheat leaves. J. Plant Physiol. 168, 63-71. doi: 10.1016/j.jplph.2010.05.024

Demuner, A. J., Barbosa, L. C. A., Miranda, A. C. M., Geraldo, G. C., da Silva, C. M., Giberti, S., et al. (2013). The fungal phytotoxin alternariol 9-methyl ether and some of its synthetic analogues inhibit the photosynthetic electron transport chain. J. Nat. Prod. 76, 2234-2345. doi: 10.1021/np4005882

De Oliveira, T. L. C., de Araújo Soares, R., Ramos, E. M., das Graças Cardoso, M., Alves, E., and Piccoli, R. H. (2011). Antimicrobial activity of Satureja montana L. essential oil against Clostridium perfringens type A inoculated in mortadellatype sausages formulated with different levels of sodium nitrite. Int. J. Food Microbiol. 144, 546-555. doi: 10.1016/j.ijfoodmicro.2010.11.022

Derksen, H., Rampitsch, C., and Daayf, F. (2013). Signaling cross-talk in plant disease resistance. Plant Sci. 207, 79-87. doi: 10.1016/j.plantsci.2013. 03.004

Desjardins, A. E., Hohn, T. M., and McCormick, S. P. (1993). Trichothecene biosynthesis in Fusarium species: chemistry, genetics, and significance. Microbiol. Rev. 57, 595-604.

Dewick, P. M. (2002). The biosynthesis of C5-C25 terpenoid compounds. Nat. Prod. Rep. 19, 181-222. doi: 10.1039/b002685i

de Wit, P. J. G. M., van der Burgt, A., Ökmen, B., Stergiopoulos, I., Abd-Elsalam, K. A., Aerts, A. L., et al. (2012). The genomes of the fungal plant pathogens 
Cladosporium fulvum and Dothistroma septosporum reveal adaptation to different hosts and lifestyles but also signatures of common ancestry. PLoS Genet. 8:e1003088. doi: 10.1371/journal.pgen.1003088

Dolezal, A. L., Obrian, G. R., Nielsen, D. M., Woloshuk, C. P., Boston, R. S., and Payne, G. A. (2013). Localization, morphology and transcriptional profile of Aspergillus flavus during seed colonization. Mol. Plant Pathol. 14, 898-909. doi: 10.1111/mpp.12056

Dolezal, A. L., Shu, X., OBrian, G. R., Nielsen, D. M., Woloshuk, C. P., Boston, R. S., et al. (2014). Aspergillus flavus infection induces transcriptional and physical changes in developing maize kernels. Front. Microbiol. 5:384. doi: 10.3389/fmicb.2014.00384

Dos Santos, M. O., and Furlong, E. B. (2008). Screening of antifungal and antimycotoxigenic activity of plant phenolic extracts. World Mycotoxin J. 1, 139-146. doi: 10.3920/WMJ2008.1006

Du Fall, L. A., and Solomon, P. S. (2011). Role of cereal secondary metabolites involved in mediating the outcome of plant-pathogen interactions. Metabolites 1, 64-78. doi: 10.3390/metabo1010064

Durrant, W. E., and Dong, X. (2004). Systemic acquired resistance. Annu. Rev. Phytopathol. 42, 185-209. doi: 10.1146/annurev.phyto.42.040803.140421

Ebata, Y., Yamamoto, H., and Uchiyama, T. (1998). Chemical composition of the glue from apressoria of Magnaporthe grisea. Biosci. Biotechnol. Biochem. 62, 672-674.

El-Mogy, M. M., and Alsanius, B. W. (2012). Cassia oil for controlling plant and human pathogens on fresh strawberries. Food Control 28, 157-162. doi: 10.1016/j.foodcont.2012.04.036

Espinosa-García, F. J., and Langenheim, J. H. (1991). Effects of sabinene and $\gamma$ terpinene from coastal redwood leaves acting singly or in mixtures on the growth of some of their fungus endophytes. Biochem. Syst. Ecol. 19, 643-650. doi: 10.1016/0305-1978(91)90080-J

Evidente, A., Punzo, B., Andolfi, A., Berestetskiy, A., and Motta, A. (2009). Alternethanoxins A and B, polycyclic ethanones produced by Alternaria sonchi, potential mycoherbicides for Sonchus arvensis biocontrol. J. Agric. Food Chem. 57, 6656-6660. doi: 10.1021/jf9014944

Feng, G. H., and Leonard, T. J. (1998). Culture conditions control expression of the genes for aflatoxin and sterigmatocystin biosynthesis in Aspergillus parasiticus and A. nidulans. Appl. Environ. Microbiol. 64, 2275-2277.

Fitzpatrick, D. A. (2012). Horizontal gene transfer in fungi. FEMS Microbiol. Lett. 329, 1-8. doi: 10.1111/j.1574-6968.2011.02465.x

Flaishman, M. A., and Kolattukudy, P. E. (1994). Timing of fungal invasion using host's ripening hormone as a signal. Proc. Natl. Acad. Sci. U.S.A. 91, 6579-6583.

Foroud, N. A., and Eudes, F. (2009). Trichothecenes in cereal grains. Int. J. Mol. Sci. 10, 147-173. doi: 10.3390/ijms10010147

Fountain, J. C., Scully, B. T., Ni, X., Kemerait, R. C., Lee, R. D., Chen, Z. Y., et al. (2014). Environmental influences on maize-Aspergillus flavus interactions and aflatoxin production. Front. Microbiol. 5:40. doi: 10.3389/fmicb.2014.00040

Friesen, T. L., Faris, J. D., Solomon, P. S., and Oliver, R. P. (2008). Host-specific toxins: effectors of necrotrophic pathogenicity. Cell. Microbiol. 10, 1421-1428. doi: $10.1111 /$ j.1462-5822.2008.01153.x

Gaffoor, I., and Trail, F. (2006). Characterization of two polyketide synthase genes involved in zearalenone biosynthesis in Gibberella zeae. Appl. Environ. Microbiol. 72, 1793-1799. doi: 10.1128/AEM.72.3.1793-1799.2006

Gao, S., Li, Y., Gao, J., Suo, Y., Fu, K., Li, Y., et al. (2014). Genome sequence and virulence variation-related transcriptome profiles of Curvularia lunata, an important maize pathogenic fungus. BMC Genomics 15:627. doi: 10.1186/14712164-15-627

Garcia, D., Ramos, A. J., Sanchis, V., and Marín, S. (2012). Effect of Equisetum arvense and Stevia rebaudiana extracts on growth and mycotoxin production by Aspergillus flavus and Fusarium verticillioides in maize seeds as affected by water activity. Int. J. Food Microbiol. 153, 21-27. doi: 10.1016/j.ijfoodmicro.2011.10.010

Gardiner, D. M., Kazan, K., Praud, S., Torney, F. J., Rusu, A., and Manners, J. M. (2010). Early activation of wheat polyamine biosynthesis during Fusarium head blight implicates putrescine as an inducer of trichothecene mycotoxin production. BMC Plant Biol. 10:289. doi: 10.1186/1471-222910-289

Ghebremeskel, M., and Langseth, W. (2001). The occurrence of culmorin and hydroxy-culmorins in cereals. Mycopathologia 152, 103-108. doi: 10.1023/A:1012479823193
Gilbert, R. D., Johnson, A. M., and Dean, R. A. (1996). Chemical signals responsible for appressorium formation in the rice blast fungus Magnaporthe grisea. Physiol. Mol. Plant Pathol. 48, 335-346. doi: 10.1006/pmpp.1996.0027

Glazebrook, J. (2005). Contrasting mechanisms of defense against biotrophic and necrotrophic pathogens. Annu. Rev. Phytopathol. 43, 205-227. doi: 10.1146/annurev.phyto.43.040204.135923

Gonzalez Garcia, V., Portal Onco, M. A., and Rubio Susan, V. (2006). Review. Biology and systematics of the form genus Rhizoctonia. Spanish J. Agric. Res. 4, 55. doi: 10.5424/sjar/2006041-178

Govrin, E. M., and Levine, A. (2002). Infection of Arabidopsis with a necrotrophic pathogen, Botrytis cinerea, elicits various defense responses but does not induce systemic acquired resistance (SAR). Plant Mol. Biol. 48, 267-276. doi: 10.1023/A:1013323222095

Grayer, R. J., and Kokubun, T. (2001). Plant-fungal interactions: the search for phytoalexins and other antifungal compounds from higher plants. Phytochemistry 56, 253-263. doi: 10.1016/S0031-9422(00)00450-7

Guo, C. J., and Wang, C. C. C. (2014). Recent advances in genome mining of secondary metabolites in Aspergillus terreus. Front. Microbiol. 5:717. doi: 10.3389/fmicb.2014.00717

Halloin, J. M., De Zoeten, G. A., and Walker, J. C. (1970). The effects of tentoxin on chlorophyll synthesis and plastid structure in cucumber and cabbage. Plant Physiol. 45, 310-314.

Hansen, F. T., Gardiner, D. M., Lysøe, E., Fuertes, P. R., Tudzynski, B., Wiemann, P., et al. (2015). An update to polyketide synthase and non-ribosomal synthetase genes and nomenclature in Fusarium. Fungal Genet. Biol. 75, 20-29. doi: 10.1016/j.fgb.2014.12.004

Hatta, R., Ito, K., Hosaki, Y., Tanaka, T., Tanaka, A., Yamamoto, M., et al. (2002). A conditionally dispensable chromosome controls host-specific pathogenicity in the fungal plant pathogen Alternaria alternata. Genetics 161, 59-70.

Hauser, F., Waadt, R., and Schroeder, J. I. (2011). Evolution of abscisic acid synthesis and signaling mechanisms. Curr. Biol. 21, R346-R355. doi: 10.1016/j.cub.2011.03.015

Hedden, P., Phillips, A. L., Rojas, M. C., Carrera, E., and Tudzynski, B. (2001). Gibberellin biosynthesis in plants and fungi: a case of convergent evolution? J. Plant Growth Regul. 20, 319-331. doi: 10.1007/s003440010037

Hegde, Y., and Kolattukudy, P. E. (1997). Cuticular waxes relieve self-inhibition of germination and appressorium formation by the conidia of Magnaporthe grisea. Physiol. Mol. Plant Pathol. 51, 75-84. doi: 10.1006/pmpp.1997.0105

Horbach, R., Navarro-Quesada, A. R., Knogge, W., and Deising, H. B. (2011). When and how to kill a plant cell: infection strategies of plant pathogenic fungi. J. Plant Physiol. 168, 51-62. doi: 10.1016/j.jplph.2010.06.014

Horowitz Brown, S., Zarnowski, R., Sharpee, W. C., and Keller, N. P. (2008). Morphological transitions governed by density dependence and lipoxygenase activity in Aspergillus flavus. Appl. Environ. Microbiol. 74, 5674-5685. doi: 10.1128/AEM.00565-08

Howard, R. J., Ferrari, M. A., Roach, D. H., and Money, N. P. (1991). Penetration of hard substrates by a fungus employing enormous turgor pressures. Proc. Natl. Acad. Sci. U.S.A. 88, 11281-11284. doi: 10.1073/pnas.88.24.11281

Howard, R. J., and Valent, B. (1996). Breaking and entering: host penetration by the fungal rice blast pathogen Magnaporthe grisea. Annu. Rev. Microbiol. 50, 491-512. doi: 10.1146/annurev.micro.50.1.491

Howlett, B. J. (2006). Secondary metabolite toxins and nutrition of plant pathogenic fungi. Curr. Opin. Plant Biol. 9, 371-375. doi: 10.1016/j.pbi.2006.05.004

Hu, J., Chen, C., Peever, T., Dang, H., Lawrence, C., and Mitchell, T. (2012). Genomic characterization of the conditionally dispensable chromosome in Alternaria arborescens provides evidence for horizontal gene transfer. BMC Genomics 13:171. doi: 10.1186/1471-2164-13-171

Huffaker, A., Kaplan, F., Vaughan, M. M., Dafoe, N. J., Ni, X., Rocca, J. R., et al. (2011). Novel acidic sesquiterpenoids constitute a dominant class of pathogen-induced phytoalexins in maize. Plant Physiol. 156, 2082-2097. doi: 10.1104/pp.111.179457

Hwang, C. S., and Kolattukudy, P. E. (1995). Isolation and characterization of genes expressed uniquely during appressorium formation by Colletotrichum gloeosporioides conidia induced by the host surface wax. Mol. Gen. Genet. 247, 282-294.

Inderbitzin, P., Asvarak, T., and Turgeon, B. G. (2010). Six new genes required for production of T-toxin, a polyketide determinant of high virulence of 
Cochliobolus heterostrophus to maize. Mol. Plant. Microbe. Interact. 23, 458-472. doi: 10.1094/MPMI-23-4-0458

Islam, M. S., Haque, M. S., Islam, M. M., Emdad, E. M., Halim, A., Hossen, Q. M. M., et al. (2012). Tools to kill: genome of one of the most destructive plant pathogenic fungi Macrophomina phaseolina. BMC Genomics 13:493. doi: 10.1186/1471-2164-13-493

Ito, S. I., Ihara, T., Tamura, H., Tanaka, S., Ikeda, T., Kajihara, H., et al. (2007). alpha-Tomatine, the major saponin in tomato, induces programmed cell death mediated by reactive oxygen species in the fungal pathogen Fusarium oxysporum. FEBS Lett. 581, 3217-3222. doi: 10.1016/j.febslet.2007.06.010

Izumi, Y., Ohtani, K., Miyamoto, Y., Masunaka, A., Fukumoto, T., Gomi, K., et al. (2012). A polyketide synthase gene, ACRTS2, is responsible for biosynthesis of host-selective ACR-toxin in the rough lemon pathotype of Alternaria alternata. Mol. Plant Microbe Interact. 25, 1419-1429. doi: 10.1094/MPMI-06-12-0155-R

Janda, M., and Ruelland, E. (2014). Magical mystery tour: salicylic acid signalling. Environ. Exp. Bot. 114, 117-128. doi: 10.1016/j.envexpbot.2014.07.003

Jeandet, P., Douillet-Breuil, A. C., Bessis, R., Debord, S., Sbaghi, M., and Adrian, M. (2002). Phytoalexins from the Vitaceae: biosynthesis, phytoalexin gene expression in transgenic plants, antifungal activity, and metabolism. J. Agric. Food Chem. 50, 2731-2741. doi: 10.1021/jf011429s

Jermnak, U., Yoshinari, T., Sugiyama, Y., Tsuyuki, R., Nagasawa, H., and Sakuda, S. (2012). Isolation of methyl syringate as a specific aflatoxin production inhibitor from the essential oil of Betula alba and aflatoxin production inhibitory activities of its related compounds. Int. J. Food Microbiol. 153, 339-344. doi: 10.1016/j.ijfoodmicro.2011.11.023

Jiang, J., Liu, X., Yin, Y., and Ma, Z. (2011). Involvement of a velvet protein FgVeA in the regulation of asexual development, lipid and secondary metabolisms and virulence in Fusarium graminearum. PLoS ONE 6:e28291. doi: 10.1371/journal.pone.0028291

Jiang, J., Yun, Y., Liu, Y., and Ma, Z. (2012). FgVELB is associated with vegetative differentiation, secondary metabolism and virulence in Fusarium graminearum. Fungal Genet. Biol. 49, 653-662. doi: 10.1016/j.fgb.2012. 06.005

Karányi, Z., Holb, I., Hornok, L., Pócsi, I., and Miskei, M. (2013). FSRD: fungal stress response database. Database 2013:bat037. doi: 10.1093/database/bat037

Kato, H., Kodama, O., and Akatsuka, T. (1993). Oryzalexin E, A diterpene phytoalexin from UV-irradiated rice leaves. Phytochemistry 33, 79-81. doi: 10.1016/0031-9422(93)85399-C

Kato, H., Kodama, O., and Akatsuka, T. (1994). Oryzalexin F, a diterpene phytoalexin from UV-irradiated rice leaves. Phytochemistry 36, 299-301. doi: 10.1016/S0031-9422(00)97064-X

Kato-Noguchi, H., Ino, T., Sata, N., and Yamamura, S. (2002). Isolation and identification of a potent allelopathic substance in rice root exudates. Physiol. Plant. 115, 401-405. doi: 10.1034/j.1399-3054.2002.1150310.x

Kazan, K., and Lyons, R. (2014). Intervention of phytohormone pathways by pathogen effectors. Plant Cell 26, 2285-2309. doi: 10.1105/tpc.114.125419

Keller, N. P., Turner, G., and Bennett, J. W. (2005). Fungal secondary metabolism - from biochemistry to genomics. Nat. Rev. Microbiol. 3, 937-947. doi: 10.1038/nrmicro1286

Khan, A. L., Hamayun, M., Kim, Y.-H., Kang, S. M., Lee, J.-H., and Lee, I.-J. (2011). Gibberellins producing endophytic Aspergillus fumigatus sp. LH02 influenced endogenous phytohormonal levels, isoflavonoids production and plant growth in salinity stress. Process Biochem. 46, 440-447. doi: 10.1016/j.procbio. 2010.09 .013

Kim, J.-A., Cho, K., Singh, R., Jung, Y.-H., Jeong, S.-H., Kim, S.-H., et al. (2009). Rice OsACDR1 (Oryza sativa accelerated cell death and resistance 1) is a potential positive regulator of fungal disease resistance. Mol. Cells 28, 431-439. doi: 10.1007/s10059-009-0161-5

Kimura, M., Tokai, T., Takahashi-Ando, N., Ohsato, S., and Fujimura, M. (2007). Molecular and genetic studies of Fusarium trichothecene biosynthesis: pathways, genes, and evolution. Biosci. Biotechnol. Biochem. 71, 2105-2123. doi: $10.1271 /$ bbb.70183

Kimura, N., and Tsuge, T. (1993). Gene cluster involved in melanin biosynthesis of the filamentous fungus Alternaria alternata. J. Bacteriol. 175, 4427-4435.

Kliebenstein, D. J., Rowe, H. C., and Denby, K. J. (2005). Secondary metabolites influence Arabidopsis/Botrytis interactions: variation in host production and pathogen sensitivity. Plant J. 44, 25-36. doi: 10.1111/j.1365-313X.2005.02508.x
Kodama, O., Miyakawa, J., Akatsuka, T., and Kiyosawa, S. (1992). Sakuranetin, a flavanone phytoalexin from ultraviolet-irradiated rice leaves. Phytochemistry 31, 3807-3809. doi: 10.1016/S0031-9422(00)97532-0

Kodama, O., Suzuki, T., Miyakawa, J., and Akatsuka, T. (1988). Ultraviolet-induced accumulation of phytoalexins in rice leaves. Agric. Biol. Chem. 52, 2469-2473.

Koga, J., Ogawa, N., Yamauchi, T., Kikuchi, M., Ogasawara, N., and Shimura, M. (1997). Functional moiety for the antifungal activity of phytocassane E, a diterpene phytoalexin from rice. Phytochemistry 44, 249-253. doi: 10.1016/S0031-9422(96)00534-1

Koga, J., Shimura, M., Oshima, K., Ogawa, N., Yamauchi, T., and Ogasawara, N. (1995). Phytocassanes A, B, C and D, novel diterpene phytoalexins from rice, Oryza sativa L. Tetrahedron 51, 7907-7918. doi: 10.1016/0040-4020(95) 00423-6

Kolattukudy, P. E., Rogers, L. M., Li, D., Hwang, C. S., and Flaishman, M. A. (1995) Surface signaling in pathogenesis. Proc. Natl. Acad. Sci. U.S.A. 92, 4080-4087. doi: 10.1073/pnas.92.10.4080

Kono, Y., Sekido, S., Yamaguchi, I., Kondo, H., Suzuki, Y., Neto, G. C., et al. (1991). Structures of two novel pyriculol-related compounds and identification of naturally produced epipyriculol from Pyricularia oryzae. Agric. Biol. Chem. 55, 2785-2791.

Kroken, S., Glass, N. L., Taylor, J. W., Yoder, O. C., and Turgeon, B. G. (2003). Phylogenomic analysis of type I polyketide synthase genes in pathogenic and saprobic ascomycetes. Proc. Natl. Acad. Sci. U.S.A. 100, 15670-15675. doi: 10.1073/pnas.2532165100

Kroll, K., Pähtz, V., and Kniemeyer, O. (2014). Elucidating the fungal stress response by proteomics. J. Proteomics 97, 151-163. doi: 10.1016/j.jprot.2013.06.001

Kwon, Y. S., Kim, S. G., Chung, W. S., Bae, H., Jeong, S. W., Shin, S. C., et al. (2014). Proteomic analysis of Rhizoctonia solani AG-1 sclerotia maturation. Fungal Biol. 118, 433-443. doi: 10.1016/j.funbio.2014. 02.001

Langcake, P., and Pryce, R. J. (1976). The production of resveratrol by Vitis vinifera and other members of the Vitaceae as a response to infection or injury. Physiol. Plant Pathol. 9, 77-86. doi: 10.1016/0048-4059(76)90077-1

Langseth, W., Ghebremeskel, M., Kosiak, B., Kolsaker, P., and Miller, D. (2001). Production of culmorin compounds and other secondary metabolites by Fusarium culmorum and F. graminearum strains isolated from Norwegian cereals. Mycopathologia 152, 23-34. doi: 10.1023/A:10119643 06510

Laskay, G., Farkas, T., and Lehoczki, E. (1985). Cerulenin-induced changes in lipid and fatty acid content of chloroplasts in detached greening barley leaves. J. Plant Physiol. 118, 267-275. doi: 10.1016/S0176-1617(85)80228-5

Lee, W. S., Devonshire, J. B., Hammond-Kosack, K. E., Rudd, J. J., and Kanyuka, K. K. (2015). Deregulation of plant cell death through disruption of chloroplast functionality affects asexual sporulation of Zymoseptoria tritici on wheat. Mol. Plant Microbe Interact. 28, 590-604. doi: 10.1094/MPMI-10-140346-R

Leite, B., and Nicholson, R. L. (1992). Mycosporine-alanine: a self-inhibitor of germination from the conidial mucilage of Colletotrichum graminicola. Exp. Mycol. 16, 76-86. doi: 10.1016/0147-5975(92)90043-Q

Levings, I. I. I., C. S., Rhoads, D. M., and Siedow, J. N. (1995). Molecular interactions of Bipolaris maydis T-toxin and maize. Can. J. Bot. 73, 483-489. doi: 10.1139/b95-286

Li, Y., Huang, F., Lu, Y., Shi, Y., Zhang, M., Fan, J., et al. (2013). Mechanism of plant-microbe interaction and its utilization in diseaseresistance breeding for modern agriculture. Physiol. Mol. Plant Pathol. 83, 51-58. doi: 10.1016/j.pmpp.2013.05.001

Liu, W., Zhou, X., Li, G., Li, L., Kong, L., Wang, C., et al. (2011). Multiple plant surface signals are sensed by different mechanisms in the rice blast fungus for appressorium formation. PLoS Pathog. 7:e1001261. doi: 10.1371/journal.ppat.1001261

Ludwig-Müller, J. (2011). Auxin conjugates: their role for plant development and in the evolution of land plants. J. Exp. Bot. 62, 1757-1773. doi: $10.1093 /$ jxb/erq412

Ludwig-Müller, J. (2015). Bacteria and fungi controlling plant growth by manipulating auxin: balance between development and defense. J. Plant Physiol. 172, 4-12. doi: 10.1016/j.jplph.2014.01.002 
Maggio-Hall, L. A., Wilson, R. A., and Keller, N. P. (2005). Fundamental contribution of beta-oxidation to polyketide mycotoxin production in planta. Mol. Plant Microbe Interact. 18, 783-793. doi: 10.1094/MPMI-18-0783

Manamgoda, D. S., Rossman, A. Y., Castlebury, L. A., Crous, P. W., Madrid, H., Chukeatirote, E., et al. (2014). The genus Bipolaris. Stud. Mycol. 79, 221-288. doi: 10.1016/j.simyco.2014.10.002

Markham, J. E., and Hille, J. (2001). Host-selective toxins as agents of cell death in plant-fungus interactions. Mol. Plant Pathol. 2, 229-239. doi: 10.1046/j.14646722.2001.00066.x

Marsh, S. F., and Payne, G. A. (1984). Preharvest infection of corn silks and kernels by Aspergillus flavus. Phytopathology 74, 1284-1289.

Mehrabi, R., Bahkali, A. H., Abd-Elsalam, K. A., Moslem, M., Ben M’barek, S., Gohari, A. M., et al. (2011). Horizontal gene and chromosome transfer in plant pathogenic fungi affecting host range. FEMS Microbiol. Rev. 35, 542-554. doi: 10.1111/j.1574-6976.2010.00263.x

Mendgen, K., and Hahn, M. (2002). Plant infection and the establishment of fungal biotrophy. Trends Plant Sci. 7, 352-356. doi: 10.1016/S1360-1385(02)02297-5

Merhej, J., Urban, M., Dufresne, M., Hammond-Kosack, K. E., Richard-Forget, F., and Barreau, C. (2012). The velvet gene, FgVe1, affects fungal development and positively regulates trichothecene biosynthesis and pathogenicity in Fusarium graminearum. Mol. Plant Pathol. 13, 363-374. doi: 10.1111/j.13643703.2011.00755.x

Meyer, W., Lax, A., Templeton, G., and Brannon, M. (1983). The structure of gloeosporone, a novel germination self-inhibitor from conidia of Colletotrichum gloeosporioides. Tetrahedron Lett. 24, 5059-5062.

Miersch, O., Bohlmann, H., and Wasternack, C. (1999). Jasmonates and related compounds from Fusarium oxysporum. Phytochemistry 50, 517-523. doi: 10.1016/S0031-9422(98)00596-2

Mueller-Riebau, F., Berger, B., and Yegen, O. (1995). Chemical composition and fungitoxic properties to phytopathogenic fungi of essential oils of selected aromatic plants growing wild in turkey. J. Agric. Food Chem. 43, 2262-2266. doi: $10.1021 /$ jf00056a055

Nesher, I., Barhoom, S., and Sharon, A. (2008). Cell cycle and cell death are not necessary for appressorium formation and plant infection in the fungal plant pathogen Colletotrichum gloeosporioides. BMC Biol. 6:9. doi: 10.1186/17417007-6-9

Nishimura, S., and Kohmoto, K. (1983). Host-specific toxins and chemical structures from Alternaria species. Annu. Rev. Phytopathol. 21, 87-116. doi: 10.1146/annurev.py.21.090183.000511

Nishiuchi, T., Masuda, D., Nakashita, H., Ichimura, K., Shinozaki, K., Yoshida, S., et al. (2006). Fusarium phytotoxin trichothecenes have an elicitor-like activity in Arabidopsis thaliana, but the activity differed significantly among their molecular species. Mol. Plant Microbe Interact. 19, 512-520. doi: 10.1094/MPMI-19-0512

Ohtake, M., Yamamoto, H., and Uchiyama, T. (1999). Influences of metabolic inhibitors and hydrolytic enzymes on the adhesion of appressoria of Pyricularia oryzae to wax-coated cover-glasses. Biosci. Biotechnol. Biochem. 63, 978-982.

Oide, S., Moeder, W., Krasnoff, S., Gibson, D., Haas, H., Yoshioka, K., et al. (2006). NPS6, encoding a nonribosomal peptide synthetase involved in siderophoremediated iron metabolism, is a conserved virulence determinant of plant pathogenic ascomycetes. Plant Cell 18, 2836-2853. doi: 10.1105/tpc.106.045633

Osbourn, A. (1996). Saponins and plant defence-a soap story. Trends Plant Sci. 1, 4-9. doi: 10.1016/S1360-1385(96)80016-1

Otani, H., Kohmoto, K., and Kodama, M. (1995). Alternaria toxins and their effects on host plants. Can. J. Bot. 73, 453-458. doi: 10.1139/b95-282

Paciolla, C., Dipierro, N., Mulè, G., Logrieco, A., and Dipierro, S. (2004). The mycotoxins beauvericin and T-2 induce cell death and alteration to the ascorbate metabolism in tomato protoplasts. Physiol. Mol. Plant Pathol. 65, 49-56. doi: 10.1016/j.pmpp.2004.07.006

Paiardini, A., Aducci, P., Cervoni, L., Cutruzzolà, F., Di Lucente, C., Janson, G., et al. (2014). The phytotoxin fusicoccin differently regulates 14-3-3 proteins association to mode III targets. IUBMB Life 66, 52-62. doi: 10.1002/iub.1239

Palencia, E. R., Hinton, D. M., and Bacon, C. W. (2010). The black Aspergillus species of maize and peanuts and their potential for mycotoxin production. Toxins (Basel) 2, 399-416. doi: 10.3390/toxins2040399

Palmer, C. L., and Skinner, W. (2002). Mycosphaerella graminicola: latent infection, crop devastation and genomics. Mol. Plant Pathol. 3, 63-70. doi: 10.1046/j.1464-6722.2002.00100.x
Panaccione, D. G. (1993). The fungal genus Cochliobolus and toxin-mediated plant disease. Trends Microbiol. 1, 14-20.

Panstruga, R. (2003). Establishing compatibility between plants and obligate biotrophic pathogens. Curr. Opin. Plant Biol. 6, 320-326. doi: 10.1016/S13695266(03)00043-8

Paranidharan, V., Palaniswami, A., Vidhyasekaran, P., and Velazhahan, R. (2005). A host-specific toxin of Rhizoctonia solani triggers superoxide dismutase (SOD) activity in rice. Arch. Phytopathol. Plant Prot. 38, 151-157. doi: 10.1080/03235400500094159

Pedras, M. S. C., and Ahiahonu, P. W. K. (2005). Metabolism and detoxification of phytoalexins and analogs by phytopathogenic fungi. Phytochemistry 66, 391-411. doi: 10.1016/j.phytochem.2004.12.032

Pedras, M. S. C., Chumala, P. B., and Suchy, M. (2003). Phytoalexins from Thlaspi arvense, a wild crucifer resistant to virulent Leptosphaeria maculans: structures, syntheses and antifungal activity. Phytochemistry 64, 949-956. doi: 10.1016/S0031-9422(03)00441-2

Pedras, M. S. C., Minic, Z., and Abdoli, A. (2014). The phytoalexin camalexin induces fundamental changes in the proteome of Alternaria brassicicola different from those caused by brassinin. Fungal Biol. 118, 83-93. doi: 10.1016/j.funbio.2013.11.005

Pedras, M. S. C., and Montaut, S. (2003). Probing crucial metabolic pathways in fungal pathogens of crucifers: biotransformation of indole3-acetaldoxime, 4-hydroxyphenylacetaldoxime, and their metabolites. Bioorg. Med. Chem. 11, 3115-3120. doi: 10.1016/S0968-0896(03) 00241-4

Pedras, M. S. C., Montaut, S., and Suchy, M. (2004). Phytoalexins from the crucifer rutabaga: structures, syntheses, biosyntheses, and antifungal activity. J. Org. Chem. 69, 4471-4476. doi: 10.1021/jo049648a

Pedras, M. S. C., Sarwar, M. G., Suchy, M., and Adio, A. M. (2006). The phytoalexins from cauliflower, caulilexins A, B and C: isolation, structure determination, syntheses and antifungal activity. Phytochemistry 67, 1503-1509. doi: 10.1016/j.phytochem.2006. 05.020

Peng, X. L., Xu, W. T., Wang, Y., Huang, K. L., Liang, Z. H., Zhao, W. W., et al. (2010). Mycotoxin Ochratoxin A-induced cell death and changes in oxidative metabolism of Arabidopsis thaliana. Plant Cell Rep. 29, 153-161. doi: 10.1007/s00299-009-0808-x

Perez-Nadales, E., Almeida Nogueira, M. F., Baldin, C., Castanheira, S., El Ghalid, M., Grund, E., et al. (2014). Fungal model systems and the elucidation of pathogenicity determinants. Fungal Genet. Biol. 70, 42-67. doi: 10.1016/j.fgb.2014.06.011

Perry, N. B., and Foster, L. M. (1994). Antiviral and antifungal flavonoids, plus a triterpene from Hebe cupressoides. Planta Medica 60, 491-492.

Peters, R. J. (2006). Uncovering the complex metabolic network underlying diterpenoid phytoalexin biosynthesis in rice and other cereal crop plants. Phytochemistry 67, 2307-2317. doi: 10.1016/j.phytochem.2006. 08.009

Petti, C., Reiber, K., Ali, S. S., Berney, M., and Doohan, F. M. (2012). Auxin as a player in the biocontrol of Fusarium head blight disease of barley and its potential as a disease control agent. BMC Plant Biol. 12:224. doi: 10.1186/14712229-12-224

Picot, A., Barreau, C., Pinson-Gadais, L., Piraux, F., Caron, D., Lannou, C., et al. (2011). The dent stage of maize kernels is the most conducive for fumonisin biosynthesis under field conditions. Appl. Environ. Microbiol. 77, 8382-8390. doi: 10.1128/AEM.05216-11

Pierpoint, W. S. (2000). Why should plants make medicine - don't they do enough for mankind already? Biochemistry (Lond.) 22, 37-40.

Podila, G. K., Rogers, L. M., and Kolattukudy, P. E. (1993). Chemical signals from avocado surface wax trigger germination and appressorium formation in Colletotrichum gloeosporioides. Plant Physiol. 103, 267-272.

Raffaele, S., Leger, A., and Roby, D. (2009). Very long chain fatty acid and lipid signaling in the response of plants to pathogens. Plant Signal. Behav. 4, 94-99. doi: $10.4161 / p s b \cdot 4.2 .7580$

Ren, Y. Y., and West, C. A. (1992). Elicitation of diterpene biosynthesis in rice (Oryza sativa L.) by chitin. Plant Physiol. 99, 1169-1178.

Rocha, O., Ansari, K., and Doohan, F. M. (2005). Effects of trichothecene mycotoxins on eukaryotic cells: a review. Food Addit. Contam. 22, 369-378. doi: 10.1080/02652030500058403 
Ruan, Y., Kotraiah, V., and Straney, D. C. (1995). Flavonoids stimulate spore germination in Fusarium solani pathogenic on legumes in a manner sensitive to inhibitors of cAMP-dependent protein kinase. MPMI 8, 929-938.

Saddiq, A. A., and Khayyat, S. A. (2010). Chemical and antimicrobial studies of monoterpene: Citral. Pestic. Biochem. Physiol. 98, 89-93. doi: 10.1016/j.pestbp.2010.05.004

Saha, D., Fetzner, R., Burkhardt, B., Podlech, J., Metzler, M., Dang, H., et al. (2012). Identification of a polyketide synthase required for alternariol (AOH) and alternariol-9-methyl ether (AME) formation in Alternaria alternata. PLoS ONE 7:e40564. doi: 10.1371/journal.pone.0040564

Scarpari, M., Punelli, M., Scala, V., Zaccaria, M., Nobili, C., Ludovici, M., et al. (2014). Lipids in Aspergillus flavus-maize interaction. Front. Microbiol. 5:74. doi: $10.3389 /$ fmicb.2014.00074

Scharf, D. H., Heinekamp, T., and Brakhage, A. A. (2014). Human and plant fungal pathogens: the role of secondary metabolites. PLoS Pathog. 10:e1003859. doi: 10.1371/journal.ppat.1003859

Schuhegger, R., Rauhut, T., and Glawischnig, E. (2007). Regulatory variability of camalexin biosynthesis. J. Plant Physiol. 164, 636-644. doi: 10.1016/j.jplph.2006.04.012

Schulze-Lefert, P., and Panstruga, R. (2003). Establishment of biotrophy by parasitic fungi and reprogramming of host cells for disease resistance. Annu. Rev. Phytopathol. 41, 641-667. doi: 10.1146/annurev.phyto.41.061002. 083300

Scott, P. M. (2001). Analysis of agricultural commodities and foods for Alternaria mycotoxins. J. AOAC Int. 84, 1809-1817.

Segarra, G., Van der Ent, S., Trillas, I., and Pieterse, C. M. J. (2009). MYB72, a node of convergence in induced systemic resistance triggered by a fungal and a bacterial beneficial microbe. Plant Biol. (Stuttg.) 11, 90-96. doi: 10.1111/j.14388677.2008.00162.x

Shah, J., Chaturvedi, R., Chowdhury, Z., Venables, B., and Petros, R. A. (2014). Signaling by small metabolites in systemic acquired resistance. Plant J. 79, 645-658. doi: 10.1111/tpj.12464

Sieber, C. M. K., Lee, W., Wong, P., Münsterkötter, M., Mewes, H. W., Schmeitzl, C., et al. (2014). The Fusarium graminearum genome reveals more secondary metabolite gene clusters and hints of horizontal gene transfer. PLoS ONE 9:e110311. doi: 10.1371/journal.pone.0110311

Sinha, R. P., Singh, S. P., and Häder, D. P. (2007). Database on mycosporines and mycosporine-like amino acids (MAAs) in fungi, cyanobacteria, macroalgae, phytoplankton and animals. J. Photochem. Photobiol. B. 89, 29-35. doi: 10.1016/j.jphotobiol.2007.07.006

Skamnioti, P., and Gurr, S. J. (2009). Against the grain: safeguarding rice from rice blast disease. Trends Biotechnol. 27, 141-150. doi: 10.1016/j.tibtech.2008. 12.002

Spanu, P. D., Abbott, J. C., Amselem, J., Burgis, T. A., Soanes, D. M., Stüber, K., et al. (2010). Genome expansion and gene loss in powdery mildew fungi reveal tradeoffs in extreme parasitism. Science 330, 1543-1546. doi: $10.1126 /$ science. 1194573

Spassieva, S. D., Markham, J. E., and Hille, J. (2002). The plant disease resistance gene Asc-1 prevents disruption of sphingolipid metabolism during AAL-toxininduced programmed cell death. Plant J. 32, 561-572. doi: 10.1046/j.1365313X.2002.01444.x

Stanley, M. S., Callow, M. E., Perry, R., Alberte, R. S., Smith, R., and Callow, J. A. (2002). Inhibition of fungal spore adhesion by zosteric acid as the basis for a novel, nontoxic crop protection technology. Phytopathology 92, 378-383. doi: 10.1094/PHYTO.2002.92.4.378

Stępień, Ł., Waśkiewicz, A., and Wilman, K. (2015). Host extract modulates metabolism and fumonisin biosynthesis by the plant-pathogenic fungus Fusarium proliferatum. Int. J. Food Microbiol. 193, 74-81. doi: $10.1016 /$ j.ijfoodmicro.2014.10.020

Stergiopoulos, I., Collemare, J., Mehrabi, R., and De Wit, P. J. G. M. (2013). Phytotoxic secondary metabolites and peptides produced by plant pathogenic Dothideomycete fungi. FEMS Microbiol. Rev. 37, 67-93. doi: 10.1111/j.15746976.2012.00349.x

St Leger, R. J., Screen, S. E., and Shams-Pirzadeh, B. (2000). Lack of host specialization in Aspergillus flavus. Appl. Environ. Microbiol. 66, 320-324. doi: 10.1128/AEM.66.1.320-324.2000

Stodart, B. J., Harvey, P. R., Neate, S. M., Melanson, D. L., and Scott, E. S. (2007). Genetic variation and pathogenicity of anastomosis group 2 isolates of Rhizoctonia solani in Australia. Mycol. Res. 111, 891-900. doi: 10.1016/j.mycres.2007.05.008

Suryanarayanan, T. S., Thirunavukkarasu, N., Govindarajulu, M. B., Sasse, F., Jansen, R., and Murali, T. S. (2009). Fungal endophytes and bioprospecting. Fungal Biol. Rev. 23, 9-19. doi: 10.1016/j.fbr.2009. 07.001

Tada, Y., Kusaka, K., Betsuyaku, S., Shinogi, T., Sakamoto, M., Ohura, Y., et al. (2005). Victorin triggers programmed cell death and the defense response via interaction with a cell surface mediator. Plant Cell Physiol. 46, 1787-1798. doi: 10.1093/pcp/pci193

Takanashi, K., Takahashi, H., Sakurai, N., Sugiyama, A., Suzuki, H., Shibata, D., et al. (2012). Tissue-specific transcriptome analysis in nodules of Lotus japonicus. Mol. Plant Microbe Interact. 25, 869-876. doi: 10.1094/MPMI-0112-0011-R

Talbot, N. J. (2003). On the trail of a cereal killer: exploring the biology of Magnaporthe grisea. Annu. Rev. Microbiol. 57, 177-202. doi: 10.1146/annurev.micro.57.030502.090957

Talbot, N. J., McCafferty, H. R. K., Ma, M., Moore, K., and Hamer, J. E. (1997). Nitrogen starvation of the rice blast fungus Magnaporthe grisea may act as an environmental cue for disease symptom expression. Physiol. Mol. Plant Pathol. 50, 179-195. doi: 10.1006/pmpp.1997.0081

Tamogani, S., Mitani, M., Kodama, O., and Akatsuka, T. (1993). Oryzalexin S structure: a new stemarane-type rice plant phytoalexin and its biogenesis. Tetrahedron 49, 2025-2032. doi: 10.1016/S0040-4020(01)86302-X

Tanaka, E., Koga, H., and Mori, M. M. (2011). Auxin production by the rice blast fungus and its localization in host tissue. J. Phytopathol. 159, 522-530. doi: 10.1111/j.1439-0434.2011.01799.x

Tani, H., Koshino, H., Sakuno, E., Cutler, H. G., and Nakajima, H. (2006). Botcinins $\mathrm{E}$ and $\mathrm{F}$ and botcinolide from Botrytis cinerea and structural revision of botcinolides. J. Nat. Prod. 69, 722-725. doi: 10.1021/np060071x

Tanimoto, E. (2005). Regulation of root growth by plant hormones roles for auxin and gibberellins. Crit. Rev. Plant. Sci. 24, 249-265. doi: 10.1080/07352680500196108

Thines, E., Anke, H., and Sterner, O. (1998). Scytalols A, B, C, and D and other modulators of melanin biosynthesis from Scytalidium sp. 36-93. J. Antibiot. (Tokyo) 51, 387-393.

Thines, E., Anke, H., and Weber, R. W. S. (2004). Fungal secondary metabolites as inhibitors of infection-related morphogenesis in phytopathogenic fungi. Mycol. Res. 108, 14-25. doi: 10.1017/S0953756203008943

Thines, E., Daußmann, T., Semar, M., Sterner, O., and Anke, A. (1995). Fungal melanin biosynthesis inhibitors: introduction of a test system based on the production of dihydroxynaphthalene (DHN) melanin in agar cultures. $Z$. Naturforsch. 50, 813-819.

Thomma, B. P. (2003). Alternaria spp.: from general saprophyte to specific parasite. Mol. Plant Pathol. 4, 225-236. doi: 10.1046/j.1364-3703.2003.00173.x

Thomma, B. P., Nelissen, I., Eggermont, K., and Broekaert, W. F. (1999). Deficiency in phytoalexin production causes enhanced susceptibility of Arabidopsis thaliana to the fungus Alternaria brassicicola. Plant J. 19, 163-171. doi: 10.1046/j.1365-313X.1999.00513.x

Thomma, B. P., Van Esse, H. P., Crous, P. W., and De Wit, P. J. G. M. (2005) Cladosporium fulvum (syn. Passalora fulva), a highly specialized plant pathogen as a model for functional studies on plant pathogenic Mycosphaerellaceae. Mol. Plant Pathol. 6, 379-393. doi: 10.1111/j.1364-3703.2005.00292.x

Thuleau, P., Graziana, A., Rossignol, M., Kauss, H., Auriol, P., and Ranjeva, R. (1988). Binding of the phytotoxin zinniol stimulates the entry of calcium into plant protoplasts. Proc. Natl. Acad. Sci. U.S.A. 85, 5932-5935.

Tiedemann, A. V. (1997). Evidence for a primary role of active oxygen species in induction of host cell death during infection of bean leaves with Botrytis cinerea. Physiol. Mol. Plant Pathol. 50, 151-166. doi: 10.1006/pmpp.1996. 0076

Todd, J. S., Zimmerman, R. C., Crews, P., and Alberte, R. S. (1993). The antifouling activity of natural and synthetic phenol acid sulphate esters. Phytochemistry 34 , 401-404. doi: 10.1016/0031-9422(93)80017-M

Tokai, T., Koshino, H., Takahashi-Ando, N., Sato, M., Fujimura, M., and Kimura, M. (2007). Fusarium Tri4 encodes a key multifunctional cytochrome P450 monooxygenase for four consecutive oxygenation steps in trichothecene biosynthesis. Biochem. Biophys. Res. Commun. 353, 412-417. doi: 10.1016/j.bbrc.2006.12.033 
Ton, J., Van Pelt, J. A., Van Loon, L. C., and Pieterse, C. M. J. (2002). Differential effectiveness of salicylate-dependent and jasmonate/ethylenedependent induced resistance in Arabidopsis. Mol. Plant Microbe Interact. 15, 27-34. doi: 10.1094/MPMI.2002.15.1.27

Tsao, R., and Zhou, T. (2000). Antifungal activity of monoterpenoids against postharvest pathogens Botrytis cinerea and Monilinia fructicola. J. Essent. Oil Res. 12, 113-121. doi: 10.1080/10412905.2000.9712057

Tsuge, T., Harimoto, Y., Akimitsu, K., Ohtani, K., Kodama, M., Akagi, Y., et al. (2013). Host-selective toxins produced by the plant pathogenic fungus Alternaria alternata. FEMS Microbiol. Rev. 37, 44-66. doi: 10.1111/j.15746976.2012.00350.x

Tsuji, J., Jackson, E. P., Gage, D. A., Hammerschmidt, R., and Somerville, S. C. (1992). Phytoalexin accumulation in Arabidopsis thaliana during the hypersensitive reaction to Pseudomonas syringae pv syringae. Plant Physiol. 98, 1304-1309.

Tsurushima, T., Ueno, T., Fukami, H., Irie, H., and Inoue, M. (1995). Germination self-inhibitors from Colletotrichum gloeosporioides f. sp. jussiaea. MPMI 8, 652-657.

Tudzynski, B. (2014). Nitrogen regulation of fungal secondary metabolism in fungi. Front. Microbiol. 5:656. doi: 10.3389/fmicb.2014.00656

Tudzynski, P., and Kokkelink, L. (2009). "Botrytis cinerea: molecular aspects of a necrotrophic life style," in Plant Relationships, ed H. B. Deising (Berlin; Heidelberg: Springer-Verlag), 29-50.

Turgeon, B. G., and Baker, S. E. (2007). Genetic and genomic dissection of the Cochliobolus heterostrophus Tox1 locus controlling biosynthesis of the polyketide virulence factor T-toxin. Adv. Genet. 57, 219-261. doi: 10.1016/S0065-2660(06)57006-3

Van der Ent, S., Van Wees, S. C. M., and Pieterse, C. M. J. (2009). Jasmonate signaling in plant interactions with resistance-inducing beneficial microbes. Phytochemistry 70, 1581-1588. doi: 10.1016/j.phytochem.2009. 06.009

Van der Ent, S., Verhagen, B. W. M., Van Doorn, R., Bakker, D., Verlaan, M. G., Pel, M. J. C., et al. (2008). MYB72 is required in early signaling steps of rhizobacteria-induced systemic resistance in Arabidopsis. Plant Physiol. 146, 1293-1304. doi: 10.1104/pp.107.113829

Van Loon, L. C., Rep, M., and Pieterse, C. M. J. (2006). Significance of inducible defense-related proteins in infected plants. Annu. Rev. Phytopathol. 44, 135-162. doi: 10.1146/annurev.phyto.44.070505.143425

Velluti, A., Marıìn, S., Gonzalez, P., Ramos, A. J., and Sanchis, V. (2004). Initial screening for inhibitory activity of essential oils on growth of Fusarium verticillioides, F proliferatum and F. graminearum on maize-based agar media. Food Microbiol. 21, 649-656. doi: 10.1016/j.fm.2004.03.009

Vidhyasekaran, P., Ponmalar, T. R., Samiyappan, R., Velazhahan, R., Vimala, R., Ramanathan, A., et al. (1997). Host-specific toxin production by Rhizoctonia solani, the rice sheath blight pathogen. Phytopathology 87, 1258-1263. doi: 10.1094/PHYTO.1997.87.12.1258

Walker, T. S., Bais, H. P., Halligan, K. M., Stermitz, F. R., and Vivanco, J. M. (2003). Metabolic profiling of root exudates of Arabidopsis thaliana. J. Agric. Food Chem. 51, 2548-2554. doi: 10.1021/jf021166h

Walton, J. D. (1996). Host-selective toxins: agents of compatibility. Plant Cell 8, 1723-1733. doi: 10.1105/tpc.8.10.1723

Walton, J. D. (2006). HC-toxin. Phytochemistry 67, 1406-1413. doi: 10.1016/j.phytochem.2006.05.033

Wang, X., Jiang, N., Liu, J., Liu, W., and Wang, G. L. (2014). The role of effectors and host immunity in plant-necrotrophic fungal interactions. Virulence 5. doi: $10.4161 /$ viru. 29798

Wang, Y. Z., and Miller, J. D. (1988). Effects of Fusarium graminearum metabolites on wheat tissue in relation to Fusarium Head Blight resistance. J. Phytopathol. 122, 118-125. doi: 10.1111/j.1439-0434.1988.tb00998.x

Wasternack, C. (2007). Jasmonates: an update on biosynthesis, signal transduction and action in plant stress response, growth and development. Ann. Bot. 100, 681-697. doi: 10.1093/aob/mcm079

Wehner, J., Antunes, P. M., Powell, J. R., Mazukatow, J., and Rillig, M. C. (2010). Plant pathogen protection by arbuscular mycorrhizas: a role for fungal diversity? Pedobiologia (Jena) 53, 197-201. doi: 10.1016/j.pedobi.2009.10.002

Wheeler, M. H., and Bell, A. A. (1988). "Melanins and their importance in pathogenic fungi," in Current Topics in Medical Mycology 2nd Edn., ed M. R. McGinnis (New York, NY: Springer), 338-387.
Wibberg, D., Jelonek, L., Rupp, O., Kröber, M., Goesmann, A., Grosch, R., et al. (2014). Transcriptome analysis of the phytopathogenic fungus Rhizoctonia solani AG1-IB 7/3/14 applying high-throughput sequencing of expressed sequence tags (ESTs). Fungal Biol. 118, 800-813. doi: 10.1016/j.funbio.2014.06.007

Wiemann, P., Brown, D. W., Kleigrewe, K., Bok, J. W., Keller, N. P., Humpf, H. U., et al. (2010). FfVell and FfLael, components of a velvet-like complex in Fusarium fujikuroi, affect differentiation, secondary metabolism and virulence. Mol. Microbiol. 77, 972-994. doi: 10.1111/j.1365-2958.2010. 07263

Wiemann, P., Sieber, C. M. K., von Bargen, K. W., Studt, L., Niehaus, E. M., Espino, J. J., et al. (2013). Deciphering the cryptic genome: genome-wide analyses of the rice pathogen Fusarium fujikuroi reveal complex regulation of secondary metabolism and novel metabolites. PLoS Pathog. 9:e1003475. doi: 10.1371/journal.ppat.1003475

Wight, W. D., Labuda, R., and Walton, J. D. (2013). Conservation of the genes for HC-toxin biosynthesis in Alternaria jesenskae. BMC Microbiol. 13:165. doi: 10.1186/1471-2180-13-165

Wilson, C. L., Solar, J. M., El Ghaouth, A., and Wisniewski, M. E. (1997). Rapid evaluation of plant extracts and essential oils for antifungal activity against Botrytis cinerea. Plant Dis. 81, 204-210.

Wilson, R. A., and Talbot, N. J. (2009). Under pressure: investigating the biology of plant infection by Magnaporthe oryzae. Nat. Rev. Microbiol. 7, 185-195. doi: $10.1038 /$ nrmicro2032

Wink, M. (2003). Evolution of secondary metabolites from an ecological and molecular phylogenetic perspective. Phytochemistry 64, 3-19. doi: 10.1016/S0031-9422(03)00300-5

Wolpert, T. J., Dunkle, L. D., and Ciuffetti, L. M. (2002). Host-selective toxins and avirulence determinants: what's in a name? Annu. Rev. Phytopathol. 40, 251-285. doi: 10.1146/annurev.phyto.40.011402.114210

Woudenberg, J. H. C., Groenewald, J. Z., Binder, M., and Crous, P. W. (2013). Alternaria redefined. Stud. Mycol. 75, 171-212. doi: 10.3114/sim0015

$\mathrm{Wu}$, J., and Ge, X. (2004). Oxidative burst, jasmonic acid biosynthesis, and taxol production induced by low-energy ultrasound in Taxus chinensis cell suspension cultures. Biotechnol. Bioeng. 85, 714-721. doi: 10.1002/bit. 10911

Xu, L., Wang, X., Luo, R., Lu, S., Guo, Z., Wang, M., et al. (2015). Secondary metabolites of rice sheath blight pathogen Rhizoctonia solani Kühn and their biological activities. J. Integr. Agric. 14, 80-87. doi: 10.1016/S20953119(14)60905-9

Yaegashi, J., Oakley, B. R., and Wang, C. C. C. (2014). Recent advances in genome mining of secondary metabolite biosynthetic gene clusters and the development of heterologous expression systems in Aspergillus nidulans. J. Ind. Microbiol. Biotechnol. 41, 433-442. doi: 10.1007/s10295-013-1386-Z

Yan, Z., Reddy, M. S., Ryu, C. M., McInroy, J. A., Wilson, M., and Kloepper, J. W. (2002). Induced systemic protection against tomato late blight elicited by plant growth-promoting rhizobacteria. Phytopathology 92, 1329-1333. doi: 10.1094/PHYTO.2002.92.12.1329

Yang, F. Z., Li, L., and Yang, B. (2012). Alternaria toxin-induced resistance against rose aphids and olfactory response of aphids to toxin-induced volatiles of rose plants. J. Zhejiang Univ. Sci. B 13, 126-135. doi: 10.1631/jzus.B11 00087

Yang, Q., Chen, Y., and Ma, Z. (2013). Involvement of BcVeA and BcVelB in regulating conidiation, pigmentation and virulence in Botrytis cinerea. Fungal Genet. Biol. 50, 63-71. doi: 10.1016/j.fgb.2012.10.003

Yao, H., and Tian, S. (2005). Effects of pre- and post-harvest application of salicylic acid or methyl jasmonate on inducing disease resistance of sweet cherry fruit in storage. Postharvest Biol. Technol. 35, 253-262. doi: 10.1016/j.postharvbio.2004.09.001

Yazaki, K. (2006). ABC transporters involved in the transport of plant secondary metabolites. FEBS Lett. 580, 1183-1191. doi: 10.1016/j.febslet.2005. 12.009

Yazaki, K., Sugiyama, A., Morita, M., and Shitan, N. (2008). Secondary transport as an efficient membrane transport mechanism for plant secondary metabolites. Phytochem. Rev. 7, 513-524. doi: 10.1007/s11101-0079079-8

Zaehle, C., Gressler, M., Shelest, E., Geib, E., Hertweck, C., and Brock, M. (2014). Terrein biosynthesis in Aspergillus terreus and its impact 
on phytotoxicity. Chem. Biol. 21, 719-731. doi: 10.1016/j.chembiol.2014. 03.010

Zhang, L., Jia, C., Liu, L., Zhang, Z., Li, C., and Wang, Q. (2011). The involvement of jasmonates and ethylene in Alternaria alternata f. sp. lycopersici toxininduced tomato cell death. J. Exp. Bot. 62, 5405-5418. doi: 10.1093/jxb/err217

Zhao, Y. (2010). Auxin biosynthesis and its role in plant development. Annu. Rev. Plant Biol. 61, 49-64. doi: 10.1146/annurev-arplant-042809-112308

Zheng, A., Lin, R., Zhang, D., Qin, P., Xu, L., Ai, P., et al. (2013). The evolution and pathogenic mechanisms of the rice sheath blight pathogen. Nat. Commun. 4, 1424. doi: $10.1038 /$ ncomms 2427
Conflict of Interest Statement: The authors declare that the research was conducted in the absence of any commercial or financial relationships that could be construed as a potential conflict of interest.

Copyright () 2015 Pusztahelyi, Holb and Pócsi. This is an open-access article distributed under the terms of the Creative Commons Attribution License (CC BY). The use, distribution or reproduction in other forums is permitted, provided the original author(s) or licensor are credited and that the original publication in this journal is cited, in accordance with accepted academic practice. No use, distribution or reproduction is permitted which does not comply with these terms. 